Journal of

Vibration and Control

\title{
Discrete Singular Convolution-Polynomial Chaos Expansion Method for Free Vibration Analysis of Non-uniform Uncertain Beams
}

\begin{tabular}{|c|c|}
\hline Journal: & Journal of Vibration and Control \\
\hline Manuscript ID & JVC-20-0117.R3 \\
\hline Manuscript Type: & Original Manuscript \\
\hline $\begin{array}{r}\text { Date Submitted by the } \\
\text { Author: }\end{array}$ & $21-$ Oct-2020 \\
\hline Complete List of Authors: & $\begin{array}{l}\text { Seçgin, Abdullah; Dokuz Eylul University, Mechanical Engineering } \\
\text { Kara, Murat; Bolu Abant Izzet Baysal Universitesi, Mechanical } \\
\text { Engineering } \\
\text { Ferguson, Neil; University of Southampton,UK }\end{array}$ \\
\hline Keywords: & $\begin{array}{l}\text { Non-uniform beam, discrete singular convolution, uncertainty, } \\
\text { Polynomial Chaos Expansion, natural frequency }\end{array}$ \\
\hline \multirow[t]{2}{*}{$\begin{array}{l}\text { Please select up to } 5 \text { subject } \\
\text { areas that best reflect the } \\
\text { content of your manuscript: }\end{array}$} & $\begin{array}{l}\text { Modal analysis, Fundamental dynamics, Modeling, Structural } \\
\text { control/vibration mitigation, Analytical methods, Waves in solids and } \\
\text { fluids }\end{array}$ \\
\hline & $\begin{array}{l}\text { This paper enhances the Discrete Singular Convolution (DSC) method for } \\
\text { free vibration analysis of non-uniform thin beams with variability in their } \\
\text { geometrical and material properties such as thickness, specific volume } \\
\text { (inverse of density) and Young's modulus. The DSC method solves the } \\
\text { differential equation of motion of a structure with a high accuracy using } \\
\text { a small number of discretization points. The method utilizes Polynomial } \\
\text { Chaos Expansion (PCE) to express these variabilities simulating } \\
\text { uncertainty in a closed form. Non-uniformity is locally provided by } \\
\text { changing the cross-section and Young's modulus of the beam along its } \\
\text { length. In this context, firstly, natural frequencies of deterministic } \\
\text { uniform and non-uniform beams are predicted via the DSC. These results } \\
\text { are compared with finite element calculations and analytical solutions (if } \\
\text { avaliable) for the purpose of verification. Next, the uncertainty of the } \\
\text { beam due to geometrical and material variabilities is modelled in a global } \\
\text { manner by PCE to predict probability distributed functions of the natural } \\
\text { frequencies. Monte Carlo simulations are then performed for validation } \\
\text { purpose. Results show that the proposed algorithm of the DSC with PCE } \\
\text { is very accurate and also efficient, regarding computation cost, in } \\
\text { handling non-uniform beams having material and geometrical } \\
\text { variabilities. Therefore it promises that it can be reliably applied to more } \\
\text { complex structures having uncertain parameters. }\end{array}$ \\
\hline
\end{tabular}




\section{SCHOLARONE" Manuscripts}




\title{
Discrete Singular Convolution-Polynomial Chaos Expansion Method for Free Vibration Analysis of Non-uniform Uncertain Beams
}

\author{
A. Seçginn, ${ }^{\mathrm{a}}$, M. Kara ${ }^{\mathrm{b}}$, N.S. Ferguson ${ }^{\mathrm{c}}$ \\ ${ }^{a}$ Department of Mechanical Engineering, Dokuz Eylül University, İmir, Turkey \\ ${ }^{b}$ Department of Mechanical Engineering, Bolu Abant Izzet Baysal University, Bolu, Turkey \\ ${ }^{\mathrm{c}}$ Institute of Sound and Vibration Research, University of Southampton, Southampton, UK \\ *Corresponding Author: abdullah.secgin@deu.edu.tr
}

\begin{abstract}
This paper enhances the Discrete Singular Convolution (DSC) method for free vibration analysis of non-uniform thin beams with variability in their geometrical and material properties such as thickness, specific volume (inverse of density) and Young's modulus. The DSC method solves the differential equation of motion of a structure with a high accuracy using a small number of discretization points. The method utilizes Polynomial Chaos Expansion (PCE) to express these variabilities simulating uncertainty in a closed form. Non-uniformity is locally provided by changing the cross-section and Young's modulus of the beam along its length. In this context, firstly, natural frequencies of deterministic uniform and non-uniform beams are predicted via the DSC. These results are compared with finite element calculations and analytical solutions (if avaliable) for the purpose of verification. Next, the uncertainty of the beam due to geometrical and material variabilities is modelled in a global manner by PCE to predict probability distributed functions of the natural frequencies. Monte Carlo simulations are then performed for validation purpose. Results show that the proposed algorithm of the DSC with PCE is very accurate and also efficient, regarding computation cost, in handling non-uniform beams having material and geometrical variabilities. Therefore it promises that it can be reliably applied to more complex structures having uncertain parameters.
\end{abstract}

Keywords - Non-uniform beam, discrete singular convolution, uncertainty, Polynomial Chaos Expansion 


\section{Introduction}

In engineering, structures generally have different geometrical shapes and sometimes they are non-uniform along the structure for engineering reasons. Non-uniformity is generally provided to reinforce the regions with different stress distributions, especially for beams which are one of the most commonly used engineering structures. It is generally accomplished by changing either the mechanical or geometrical properties in a local manner along the structure. These types of structures are called as Functionally Graded Materials (FGMs) in literature (Akgöz and Civalek, 2013; Alshorbagy et al., 2011; Sankar, 2001). However, the same structures or components manufactured by the same mass production line may exhibit different dynamic characteristics for an unpredicted reason. These variabilities are generally labelled as uncertainty. Uncertainty and variability are unavoidable, due to various reasons such as material heterogeneity, production tolerances, manufacturing defects, environmental factors, etc. A good example for variability is a work of Kompella and Bernhard (1993). Structure-borne sound at the driver position in 57 samples of Isuzu pick-up trucks, were produced in the same production line, clearly showed variability. Many experiments and practical cases in industry showed that for a realistic design, uncertainty needs to be taken into account starting in the product design stage. Besides, it is also observed that higher frequencies are much more sensitive to these variabilities. This requirement leads to the development of some simulation methods for quantifying these variabilities. Methods used in uncertainty analysis may be categorized as probabilistic and non-probabilistic methods. Non-probabilistic methods are used in cases where the statistical properties of uncertain parameters are not known, but the limits of them are known. In such methods, only the limits of the uncertain response variable are obtained. When statistics of uncertain parameters are known or properly assumed, probabilistic methods such as Monte Carlo simulation (Evans and Swartz, 2000; Rubinstein and Kroese, 2016), first and second order 
reliability methods (Hohenbichler and Rackwitz, 1989; Keane and Price, 1997), numerical integration based methods (Evans, 1972; Rahman and Xu, 2004; Seo and Kwak, 2002) and spectral methods (Ghanem and Spanos, 2003; Lucor et al., 2004; Sepahvand, 2017; Sepahvand et al., 2007, 2010) can be appropriate methodologies to be selected. Among them, Monte Carlo simulations are the most widely used technique. However, it requires significant numerous experiments/simulation sets in order to determine response statistics, which makes it inefficient. Recently, spectral methods like Karhunen-Loeve (KL) (Ghanem and Spanos, 2003) or Polynomial Chaos Expansion (PCE) (Lucor et al., 2004; Sepahvand, 2017; Sepahvand et al., 2007, 2010), are preferable amongst the researchers since the variability is defined in a set of closed form equations.

Beams are one of the most basic and thus most attracted structural element in the research studies for the test and validation purpose of newly developed methods (Bailey, 1978; Elishakoff and Johnson, 2005; Korayem et al., 2012; Korayem and Homayooni, 2017; Wei, 2001b, 2001c; Wei et al., 2002a). For example, Bailey (1978) developed a direct analytical solution, Elishakoff and Johnson (2005) introduced a closed form solution procedure and all of them tested their techniques on non-uniform beams. Tan et. al. $(2016,2018)$ demonstrated approaches for the free vibrations of cracked and non-cracked non-uniform beams. Nazemizadeh and Bakhtiari-Nejad (2015) investigated the quality factor of composite micro/nano beams employing the nonlocal Euler-Bernoulli beam theory. Similarly, Wei (2001b, 2001c; 2002a) also tested his numerical approach, Discrete Singular Convolution (DSC), on uniform bars and beams in his early studies.

The DSC method (Wei, 1999) promises great potential especially in handling high frequency structural dynamic problems. Because it has inherent global method accuracy and local method flexibility together with requiring a small number of discretization points to define the geometrical domain. The method is based on the theory of distributions and 
wavelets. The DSC method solves the governing differential equation of motion of a structure with a high accuracy using a small number of discretization points. Wei and his co-workers applied the DSC method to several different vibration problems (Wei, 2001a, 2001b, 2001c; Wei et al., 2001, 2002a, 2002b; Zhao et al., 2005). Seçgin and Sarıül (2008) adapted the DSC method to analyse vibration problems of laminated composite plates. Similarly, Civalek et. al. (Baltacioğlu et al., 2010, 2011; Civalek, 2007, 2013; Gürses et al., 2009) have made great contribution to the development of the DSC, especially for the analysis of laminated plates and nano-structures (Civalek, 2017; Gürses et al., 2012; Mercan and Civalek, 2016). Beside that, Shokrollahi et. at. (2014) investigated the natural frequencies of non-uniform bars having different combinations of cross-sections via the DSC. Civalek et. al. (2008a, 2008b, 2009; Ersoy et al., 2009, 2010) applied the DSC to more complex non-uniform structures, i.e., shell and membranes. Seçgin $(2013 ; 2012 ; 2018)$ also combined the DSC with some uncertainty analysis methods. He performed Monte Carlo simulation by using the DSC for a thin isotropic plate and laminated composite plates in Refs. (Seçgin, 2013; Seçgin et al., 2012), respectively, in order to estimate the statistical bounds of vibration via an extreme value model. In another study, Seçgin and Kara (2018) developed a closed form solution methodology for the analysis of uncertain thin beams. In that study, they showed that the DSC presents a unique advantage since the characteristic matrix obtained via the DSC is independent from physical and mechanical properties of the considered structure. Besides, the DSC method is very efficient for the higher frequencies where the uncertainty dominates, since the method uses a relatively small number of discretization points.

As far as to the authors' knowledge, there are limited number of studies on uncertain and non-uniform structures in literature (2004; 2003). Impollonia and his/her colleagues (2004; 2003) analysed static response of uncertain tapered cantilever beams via a novel response surface approach. Besides, there is no attempt yet to show the performance of the combined 
DSC and PCE for both uncertain and non-uniform structures. Therefore, this study performs such an attempt to test the methodology and applies the DSC method for more sophisticated structures.

In this study, the Discrete Singular Convolution (DSC) and Polynomial Chaos Expansion PCE are combined in order to analyse uncertain non-uniform beams. Non-uniformity is locally provided by a changing cross-section and Young's modulus of the beam along its length. However, the uncertainty is globally simulated by providing normally distributed variabilities in geometrical and material properties such as thickness, specific volume and Young's modulus. Here, the non-uniform beam is modelled via the DSC whereas uncertainty is defined by PCE in a closed form. In this context, the implementation procedure of the DSC and PCE is given in detail. Numerical analyses start with the prediction of the natural frequencies of deterministic uniform and non-uniform beams via the DSC. The results are verified by finite element calculations and analytical solutions (if possible). Then, the uncertainty of the beam due to geometrical and material variabilities is considered, and probability distribution functions of natural frequencies are determined by the DSC-PCE combination. Monte Carlo simulations are then performed for validation purpose. It is shown that the DSC-PCE combination is very accurate as well as being efficient regarding computation cost.

\section{Mathematical Considerations}

\subsection{Stochastic partial differential equation of non-uniform thin beams}

The homogeneous differential equation of motion for bending vibrations of an undamped thin beam (shown in Fig. 1) with variable thickness and Young's modulus along space is expressed as follows (Rao, 2011): 


$$
\frac{\partial^{2}}{\partial x^{2}}\left(E(x) I_{y}(x) \frac{\partial^{2} w(x, t)}{\partial x^{2}}\right)+\rho A(x) \frac{\partial^{2} w(x, t)}{\partial t^{2}}=0
$$

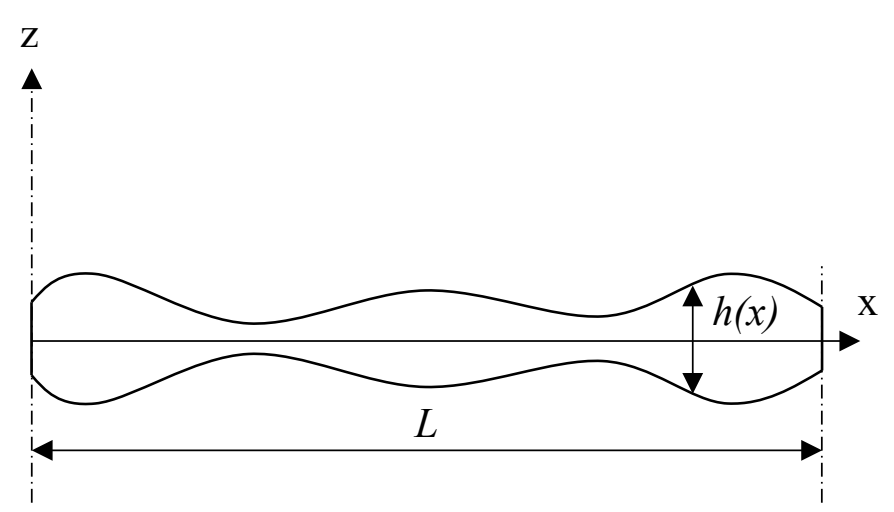

Figure 1. A beam structure with its geometrical parameters

Here, $x$ is the space variable, $\rho$ is uniform mass density, $w$ is the bending displacement in the $z$ direction, $E(x), h(x), A(x)$ and $I_{y}(x)$ are the space dependent Young's modulus, thickness, cross-sectional area and area moment of inertia about the $y$ axis, respectively. Assume that the beam has constant width $b$, the thickness and Young's modulus have the form of $h(x)=h_{0} f_{h}(x)$ and $E(x)=E f_{E}(x)$ where $h_{0}$ and $E$ are the thickness and Young's modulus at $x=0, f_{h}(x)$ and $f_{E}(x)$ represent the space dependency of thickness and the Young's modulus, respectively. In this context, the separable solution of Eq. (1) can be rewritten for harmonic free vibration response $w(x, t, \vartheta)=W(x, \vartheta) \exp \left(\mathrm{j} \omega_{n} t\right)$ with stochastic parameters $\vartheta=\left\{\vartheta_{1}, \vartheta_{2}, \vartheta_{3}\right\}$ ( $W$ is time independent stochastic vibration amplitude, $\omega_{n}$ is the natural frequency, $\vartheta_{1}, \vartheta_{2}, \vartheta_{3}$ are the uncertain parameters affecting Young's modulus, thickness and density, respectively and $\mathrm{j}=\sqrt{-1}$ ) as follows,

$$
\begin{aligned}
& \frac{1}{12} E\left(\vartheta_{1}\right) h_{0}^{2}\left(\vartheta_{2}\right) r\left(x, \vartheta_{3}\right)\left[f_{E} f_{h}^{2} W^{(4)}(x, \vartheta)+2\left(f_{E}^{(1)} f_{h}^{2}+3 f_{E} f_{h}^{(1)} f_{h}\right) W^{(3)}(x, \vartheta)\right. \\
& \left.\left.+\left(f_{E}^{(2)} f_{h}^{2}+6 f_{E}^{(1)} f_{h}^{(1)} f_{h}+6 f_{E}\left(f_{h}^{(1)}\right)^{2}+3 f_{E} f_{h}^{(2)} f_{h}\right) W^{(2)}(x, \vartheta)\right\}\right]-\lambda_{n}(\vartheta) W(x, \vartheta)=0 .
\end{aligned}
$$


Here $r\left(x, \vartheta_{3}\right)=1 / \rho\left(x, \vartheta_{3}\right)$ is defined as the specific volume. The superscripts in parenthesis shows the order of differentiation with respect to space $x$, and $\lambda_{n}=\omega_{n}^{2}$ is the eigenvalue of the structure.

\subsection{Discrete Singular Convolution}

In the DSC algorithm, the computational domain of a $1 \mathrm{D}$ system is generally divided into three different parts; structural, left and right ghost (auxiliary) domains as shown in Fig. 2. In the computational domain, a function $f(x)$ and its $n$th order derivative can be approximated via a discretized singular kernels of delta type (Wei, 2001c):

$$
f^{(n)}\left(x_{i}\right) \approx \sum_{k=-M}^{M} C_{k}^{(n)} f\left(x_{i+k}\right), \quad i=0,1,2, \ldots, M
$$

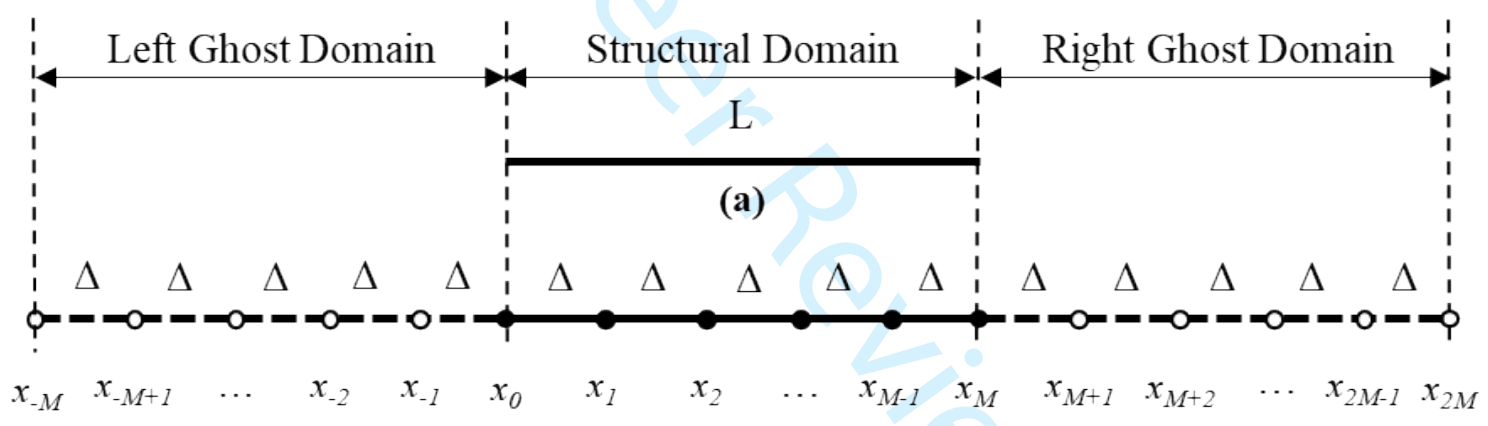

(b)

Figure 2. DSC discretization domain for 1-D structures (a) a 1D structure with length L,

b) Computational domain for the structure (Seçgin and Sarigül, 2008)

Here, $i$ represents the index of discretization points in the structural domain and $M$ stands for the number of ghost points. The function $f(x)$ is determined at uniformly distributed discretization points. The term $C_{k}^{(n)}$ is the DSC kernel and can be expressed for regularized Shannon delta kernel as (Wei, 2001c):

$$
C_{k}^{(n)}=\left.\left(\frac{d}{d x}\right)^{n}\left(\frac{\sin \left(\alpha\left(x-x_{k}\right)\right)}{\alpha\left(x-x_{k}\right)} \exp \left(-\left(x-x_{k}\right)^{2} / 2 \sigma^{2}\right)\right)\right|_{x=x_{i}},
$$


where $\alpha=\pi / \Delta$ is Nyquist frequency, $\sigma=r \Delta, \Delta$ represents the distance between the discretization points and $r$ is regularization coefficient which can be selected by trial and error to confirm accuracy, and superscript $n$ stands for the order of the derivative. One can follow the following steps in order to model a beam structure via the DSC:

1. The beam is discretized by using $M+1$ number of structural and $M$ number of ghost points as shown in Fig. 2.

2. Eq. (3) is written for each structural point.

3. Kernel coefficients $C_{k}^{(n)}$ are computed from Eq. (4)

4. Proper boundary condition implementation procedure is performed to get rid of the displacement in the ghost domains. Note that, this procedure is given in detail in Ref. (Kara and Seçgin, 2019; Seçgin and Sarigül, 2008, 2009) for clamped, simply supported and free boundary conditions.

5. Next, Eq. (3) can be written in a matrix form as an eigenvalue problem,

$$
\left(E\left(\vartheta_{1}\right) h^{2}\left(\vartheta_{2}\right) r\left(\vartheta_{3}\right)[\mathbf{D}(\mathbf{X})]-\lambda_{n}(\vartheta)[\mathbf{I}]\right)\{\mathbf{W}(\mathbf{X}, \vartheta)\}=0
$$

Here, $[\mathbf{D}(\mathbf{X})]$ is the dynamic stiffness matrix, $\mathbf{X}=\left\{X_{0}, X_{1}, \ldots, X_{M}\right\}^{T}$ represents the vector for the discretized structural points and $\mathbf{W}=\left\{W_{0}, W_{1}, \ldots, W_{M}\right\}^{T}$ is the corresponding bending displacement vector for the structural points. It should be noted that, the dynamic stiffness matrix is independent from the amplitude of physical and mechanical properties $\left(E, h_{0}\right.$ and $\left.r\right)$. Thus, in the DSC, once the matrix is calculated, one may then calculate the dynamic response and/or eigenvalues for different materials and thicknesses. To show the content of the dynamic stiffness matrix, the $i$ th row of the matrix which belongs to $(i-1)$ th structural point is given here as: 


$$
\begin{array}{r}
\{\mathbf{D}(\mathbf{X})\}_{1 \times(M+1)}=\left.\frac{1}{12}\left(f_{E} f_{h}^{2}\right)\right|_{x=X_{i-1}}\left\{\mathbf{D}^{(4)}\right\}+\left.\frac{1}{6}\left(f_{E}^{(1)} f_{h}^{2}+3 f_{E} f_{h}^{(1)} f_{h}\right)\right|_{x=X_{i-1}}\left\{\mathbf{D}^{(3)}\right\} \\
+\left.\frac{1}{12}\left(f_{E}^{(2)} f_{h}^{2}+6 f_{E}^{(1)} f_{h}^{(1)} f_{h}+6 f_{E}\left(f_{h}^{(1)}\right)^{2}+3 f_{E} f_{h}^{(2)} f_{h}\right)\right|_{x=X_{i-1}}\left\{\mathbf{D}^{(2)}\right\}
\end{array}
$$

Here, $\left\{\mathbf{D}^{(\mathbf{n})}\right\}$ is the $i$ th row of the characteristic DSC matrix of differentiation order of $n$. Note that, space dependent functions and their derivatives are calculated at $x=X_{i-1}$.

\subsection{Polynomial Chaos Expansion (PCE)}

In Polynomial Chaos Expansion (PCE), any uncertain variable $Y$ can be expressed as the sum of orthogonal polynomials (Ghanem and Spanos, 2003):

$$
\begin{aligned}
Y(\xi) & =y_{0} \psi_{0}+\sum_{i_{1}=1}^{\infty} y_{i_{1}} \psi_{1}\left(\xi_{i_{1}}\right)+\sum_{i_{1}=1}^{\infty} \sum_{i_{2}=1}^{i_{1}} y_{i_{1} i_{2}} \psi_{2}\left(\xi_{i_{1}}, \xi_{i_{2}}\right)+\sum_{i_{1}=1}^{\infty} \sum_{i_{2}=1}^{i_{1}} \sum_{i_{3}=1}^{i_{2}} y_{i_{1} i_{3} i_{3}} \psi_{3}\left(\xi_{i_{1}}, \xi_{i_{2}}, \xi_{i_{3}}\right)+\ldots \\
& =\sum_{i=0}^{\infty} y_{i} \psi_{i}(\xi)
\end{aligned}
$$

Here, $\xi=\left\{\xi_{1}, \xi_{2}, \ldots, \xi_{i_{n}}\right\}$ is the vector containing stochastic parameters, $y_{i}$ is deterministic coefficients of orthogonal polynomial basis of $\psi_{i}($.$) . Since polynomial terms are orthogonal$ to each other;

$$
\left\langle\psi_{i} \cdot \psi_{j}\right\rangle=\left\{\begin{array}{ll}
0, & \text { for } i \neq j \\
\left\langle\psi_{i}^{2}\right\rangle, & \text { for } i=j
\end{array} .\right.
$$

Here, \langle\rangle represents the mean value. In numerical calculations, it is meaningful to cease infinite series the sum of the polynomial in Eq. (7) by a finite value of terms $N_{P C}$ (Sepahvand et al., 2010):

$$
N_{P C}=\frac{(m+p) !}{m ! p !}-1
$$

Here, $p$ shows the order of polynomial, $m$ shows number of uncertain parameter $\left(\xi_{i}\right)$ to define uncertain variable $(Y)$. In PCE, unknown deterministic coefficients of the polynomials can be 
determined by using a Galerkin projection which may be described as calculating the average of the considered equation and basis polynomial function multiplication (Sepahvand et al., 2010):

$$
y_{i}=\frac{1}{\left\langle\psi_{i}^{2}\right\rangle} \int_{\Omega_{1}} \ldots \int_{\Omega_{m}}\left\langle Y, \psi_{k}(\xi)\right\rangle d \mu_{m}\left(\xi_{m}\right) \ldots d \mu_{1}\left(\xi_{1}\right)
$$

Note that, $d \mu(\xi)=\mu(\xi) d \xi$ is the probability function of the random space $(\Omega)$ of uncertain parameter $(\xi)$ and $k$ is an integer starting from zero. Several types of polynomial basis functions $\left(\psi_{i}\right)$ such as Laguerre polynomial, Jacobi polynomial, Legendre polynomial, etc. can be used in PCE, but Hermite polynomials are the most suitable one for the normal distribution (Ghanem and Spanos, 2003):

$$
H_{i}(\xi)=(-1)^{i} \exp \left(\frac{1}{2} \xi^{T} \xi\right) \frac{\partial^{i}}{\partial \xi_{i_{1}} \partial \xi_{i_{2}} \ldots \partial \xi_{i_{n}}} \exp \left(-\frac{1}{2} \xi^{T} \xi\right)
$$

In PCE, using a first order polynomial is sufficient for representation of a normal distribution with Hermite polynomials with a single uncertain parameter, so PCE then reduces to Karhunen-Love (KL) expansion $\left(N_{P C}=1\right)$.

In this study, stochastic parameters given in Section 2.1 can be redefined as $\vartheta_{i}=\left\{\xi_{i, 1}, \xi_{i, 2}, \ldots, \xi_{i, n}\right\}$. It is assumed that all uncertain variables depend on a single uncertain variable $\left(\vartheta_{i}=\xi_{i, 1}=\xi_{i}\right)$ with a normal distribution. Therefore uncertain variables can be rewritten as follows:

$$
\begin{gathered}
E\left(\vartheta_{1}\right)=\sum_{i=0}^{1} E_{i} H_{i}\left(\xi_{1}\right)=E_{0}+E_{1} \xi_{1}, \\
h^{2}\left(\vartheta_{2}\right)=\sum_{j=0}^{1} h_{j}^{2} H_{j}\left(\xi_{2}\right)=h_{0}^{2}+h_{1}^{2} \xi_{2},
\end{gathered}
$$




$$
r\left(\vartheta_{3}\right)=\sum_{k=0}^{1} r_{k} H_{k}\left(\xi_{3}\right)=r_{0}+r_{1} \xi_{3}
$$

Note that, $E_{0}, h_{0}$ and $r_{0}$ are the mean values of the Young's modulus and thickness at $x=0$, and specific volume, respectively. $E_{1}, h_{1}$ and $r_{1}$ are the standard deviations of those uncertain parameters. Eqs. (12)-(14) can be written in the vector form as:

$$
\begin{gathered}
E\left(\vartheta_{1}\right)=\left\{\begin{array}{ll}
E_{0} & E_{1}
\end{array}\right\}\left\{\begin{array}{l}
1 \\
\xi_{1}
\end{array}\right\}, \\
h^{2}\left(\vartheta_{2}\right)=\left\{\begin{array}{ll}
h_{0}^{2} & h_{1}^{2}
\end{array}\right\}\left\{\begin{array}{l}
1 \\
\xi_{2}
\end{array}\right\}, \\
r\left(\vartheta_{1}\right)=\left\{\begin{array}{ll}
r_{0} & r_{1}
\end{array}\right\}\left\{\begin{array}{l}
1 \\
\xi_{3}
\end{array}\right\} .
\end{gathered}
$$

Polynomial basis terms of the corresponding eigenvalues are written by using the tensor product of Eqs. (15)-(17);

$$
\psi_{k}\left(\xi_{1}, \xi_{2}, \xi_{3}\right)=\left\{\begin{array}{l}
1 \\
\xi_{1}
\end{array}\right\} \otimes\left\{\begin{array}{l}
1 \\
\xi_{2}
\end{array}\right\} \otimes\left\{\begin{array}{l}
1 \\
\xi_{3}
\end{array}\right\} .
$$

Here, $\otimes$ denotes the tensor product. Since the dimension of the vector $\psi_{k}\left(\xi_{1}, \xi_{2}, \xi_{3}\right)$ is $8 \times 1$, the uncertain eigenvalues are described by the summation starting from 0 to $N_{\lambda}=7$ as follows,

$$
\begin{aligned}
\lambda_{n} & =\sum_{k=0}^{N_{\lambda}} \lambda_{n, k} \psi_{k}\left(\xi_{1}, \xi_{2}, \xi_{3}\right) \\
& =\lambda_{n, 0}+\lambda_{n, 1} \xi_{1}+\lambda_{n, 3} \xi_{2}+\lambda_{n, 4} \xi_{3}+\lambda_{n, 4} \xi_{1} \xi_{2}+\lambda_{n, 5} \xi_{1} \xi_{3}+\lambda_{n, 6} \xi_{2} \xi_{3}+\lambda_{n, 7} \xi_{1} \xi_{2} \xi_{3}
\end{aligned}
$$

Substituting Eqs. (12)-(14) and Eq. (19) into Eq. (5) leads to:

$$
\left[\left(E_{0}+E_{1} \xi_{1}\right)\left(h_{0}^{2}+h_{1}^{2} \xi_{2}\right)\left(r_{0}+r_{1} \xi_{3}\right) \mathbf{D}(\mathbf{X})-\lambda_{n}\left(\xi_{1}, \xi_{2}, \xi_{3}\right) \mathbf{I}\right]\{\mathbf{W}(\mathbf{X}, \vartheta)\}=0
$$


Multiplying Eq. (20) with the $u$ th term of the orthogonal basis of $\psi_{k}$ and applying the Galerkin projection yields the final form of DSC-PCE based eigenvalue equation of a nonuniform and uncertain thin beam:

$$
\left(\begin{array}{r}
\left(E_{0}+E_{1} \xi_{1}\right)\left(h_{0}^{2}+h_{1}^{2} \xi_{2}\right)\left(r_{0}+r_{1} \xi_{3}\right) \psi_{u}\left(\xi_{1}, \xi_{2}, \xi_{3}\right) \mathbf{D}(\mathbf{X}) \\
-\lambda_{n, u} \psi_{u}^{2}\left(\xi_{1}, \xi_{2}, \xi_{3}\right) \mathbf{I}
\end{array}\right)\{\mathbf{W}(\mathbf{X}, \vartheta)\}=0
$$

One can now calculate $\lambda_{n, u}$ by changing $u$ starting from zero up to $N_{\lambda}$ in Eq. (21) by using any eigenvalue solver.

\section{Numerical studies}

In this section, free vibration analyses of a non-uniform and uncertain thin beam with simplysupported boundary conditions are performed. Material and geometrical properties of the beam are given in Table 1. The study starts with a deterministic analysis for uniform and nonuniform beams. Then, stochastic analyses are performed for the non-uniform beam with variable material and geometrical properties by using the PCE based DSC method. Both studies include a verification and convergence investigation. Numerical analyses are performed by a computer with Intel Core i5-3230M 4x2.6 GHz, 8 GB Ram, 64 Bit Win 10.

Table 1. Material and geometrical properties of the beam

\begin{tabular}{lc}
\hline Property (Unit) & Value \\
\hline Young' modulus $(\mathrm{Pa})$ & $3.25 \mathrm{E}+10$ \\
Density $\left(\mathrm{kgm}^{-3}\right)$ & 2500 \\
Thickness at $x=0(\mathrm{~m})$ & 0.25 \\
Width $(\mathrm{m})$ & 0.3 \\
Length $(\mathrm{m})$ & 15 \\
\hline
\end{tabular}




\subsection{Deterministic analysis}

Here, firstly a uniform beam is considered. The first ten natural frequencies are obtained via the DSC method for different numbers of structural points and via the finite element method (FEM) for different numbers of one dimensional beam elements. The results are compared with analytical solutions in Table 2 and an optimum number of structural points for the DSC and number of elements for FEM are determined for further analyses. In this regard, relative differences of the DSC and FEM from analytical solutions are also presented in the table. The thickness is selected as $0.25 \mathrm{~m}$ in these calculations. Note that the maximum number of the DSC points and finite elements are decided here to achieve the same analytical results in a 3digit-floating accuracy.

Table 2. Natural frequencies of the simply supported uniform beam ( $\mathrm{rad} / \mathrm{s})$

\begin{tabular}{|c|c|c|c|c|c|c|c|c|}
\hline $\begin{array}{c}\text { Mode } \\
\text { Seq. }\end{array}$ & $\begin{array}{c}\text { Analy. } \\
(\text { Rao, 2011) }\end{array}$ & $\begin{array}{c}\text { DSC } \\
\mathrm{N}=11\end{array}$ & $\begin{array}{c}\text { DSC } \\
\mathrm{N}=\mathbf{2 1} \\
\end{array}$ & $\begin{array}{c}\text { DSC } \\
\mathbf{N}=\mathbf{3 1} \\
\end{array}$ & $\begin{array}{l}\text { FEM } \\
\mathrm{N}=\mathbf{2 0}\end{array}$ & $\begin{array}{l}\text { FEM } \\
\mathrm{N}=60\end{array}$ & $\begin{array}{c}\text { FEM } \\
\mathbf{N}=\mathbf{1 2 0}\end{array}$ & $\begin{array}{c}\text { FEM } \\
\mathbf{N}=\mathbf{2 3 0}\end{array}$ \\
\hline 1 & 11.414 & 11.411 & 11.414 & 11.414 & 11.414 & 11.414 & 11.414 & 11.414 \\
\hline 2 & 45.656 & 45.667 & 45.656 & 45.656 & 45.656 & 45.656 & 45.656 & 45.656 \\
\hline 3 & 102.726 & 102.828 & 102.726 & 102.726 & 102.730 & 102.726 & 102.726 & 102.726 \\
\hline 4 & 182.624 & 183.501 & 182.624 & 182.624 & 182.644 & 182.624 & 182.624 & 182.624 \\
\hline 5 & 285.350 & 290.841 & 285.350 & 285.350 & 285.424 & 285.351 & 285.350 & 285.350 \\
\hline 6 & 410.904 & 434.686 & 410.904 & 410.904 & 411.124 & 410.907 & 410.905 & 410.904 \\
\hline 7 & 559.287 & 627.888 & 559.287 & 559.287 & 559.835 & 559.294 & 559.287 & 559.287 \\
\hline 8 & 730.497 & 858.099 & 730.497 & 730.497 & 731.707 & 730.512 & 730.498 & 730.497 \\
\hline 9 & 924.535 & 1059.665 & 924.538 & 924.535 & 926.960 & 924.566 & 924.537 & 924.535 \\
\hline 10 & 1141.401 & & 1141.427 & 1141.401 & 1145.906 & 1141.460 & 1141.405 & 1141.401 \\
\hline \multicolumn{9}{|c|}{ Error \% } \\
\hline 1 & - & $-2.78 \mathrm{E}-02$ & $-3.55 \mathrm{E}-05$ & $-4.39 \mathrm{E}-07$ & $4.22 \mathrm{E}-05$ & $4.92 \mathrm{E}-07$ & $2.80 \mathrm{E}-06$ & $8.27 \mathrm{E}-06$ \\
\hline 2 & - & $2.35 \mathrm{E}-02$ & $2.16 \mathrm{E}-06$ & $2.71 \mathrm{E}-08$ & $6.75 \mathrm{E}-04$ & $8.35 \mathrm{E}-06$ & $5.94 \mathrm{E}-07$ & $1.01 \mathrm{E}-06$ \\
\hline 3 & - & $9.94 \mathrm{E}-02$ & $-4.05 E-07$ & $-5.27 \mathrm{E}-09$ & $3.40 \mathrm{E}-03$ & $4.22 \mathrm{E}-05$ & $2.70 \mathrm{E}-06$ & 5.67E-07 \\
\hline 4 & - & $4.80 \mathrm{E}-01$ & $1.20 \mathrm{E}-07$ & $1.62 \mathrm{E}-09$ & $1.07 \mathrm{E}-02$ & $1.33 \mathrm{E}-04$ & $8.36 \mathrm{E}-06$ & $8.20 \mathrm{E}-07$ \\
\hline 5 & - & $1.92 \mathrm{E}+00$ & $-2.74 \mathrm{E}-08$ & $-6.42 \mathrm{E}-10$ & $2.60 \mathrm{E}-02$ & $3.26 \mathrm{E}-04$ & $2.04 \mathrm{E}-05$ & $1.61 \mathrm{E}-06$ \\
\hline 6 & - & $5.79 \mathrm{E}+00$ & $2.57 \mathrm{E}-07$ & $2.98 \mathrm{E}-10$ & $5.34 \mathrm{E}-02$ & $6.75 \mathrm{E}-04$ & $4.22 \mathrm{E}-05$ & $3.14 \mathrm{E}-06$ \\
\hline 7 & - & $1.23 \mathrm{E}+01$ & $3.01 \mathrm{E}-06$ & $-1.51 \mathrm{E}-10$ & $9.81 \mathrm{E}-02$ & $1.25 \mathrm{E}-03$ & $7.83 \mathrm{E}-05$ & $5.82 \mathrm{E}-06$ \\
\hline 8 & - & $1.75 \mathrm{E}+01$ & $3.26 \mathrm{E}-05$ & $8.31 \mathrm{E}-11$ & $1.66 \mathrm{E}-01$ & $2.13 \mathrm{E}-03$ & $1.33 \mathrm{E}-04$ & $9.90 \mathrm{E}-06$ \\
\hline 9 & - & $1.46 \mathrm{E}+01$ & $2.97 \mathrm{E}-04$ & $-4.72 \mathrm{E}-11$ & $2.62 \mathrm{E}-01$ & $3.40 \mathrm{E}-03$ & $2.14 \mathrm{E}-04$ & $1.59 \mathrm{E}-05$ \\
\hline 10 & - & & $2.24 \mathrm{E}-03$ & $2.80 \mathrm{E}-11$ & $3.95 \mathrm{E}-01$ & $5.18 \mathrm{E}-03$ & $3.26 \mathrm{E}-04$ & $2.42 \mathrm{E}-05$ \\
\hline
\end{tabular}


It is seen from Table 2 that the DSC accurately predicts the same analytical results, while FEM achieves the same accuracy with 230 elements. For this discretization points and number of elements, maximum relative differences are $-4.39 \mathrm{E}-07$ and $2.42 \mathrm{E}-05$ for the DSC and FEM, respectively. Therefore, $M+1=31$ for the DSC and $N=230$ for the FEM are selected in the further analyses.

Next, analysis of a non-uniform beam (the beam with variable geometry and material properties along its length) is performed. Again ten natural frequencies were determined for i) the beam with non-uniform thickness, ii) the beam with non-uniform Young's modulus and iii) the beam with non-uniform thickness and Young's modulus. In the analyses, two different forms of the spatial variations are assumed for the thickness i.e, $h_{0} f_{h}(x)=h_{0}(1+\beta x)^{2}$ and $h_{0} f_{h}(x)=h_{0}(1+\beta x)$ (non-uniformity parameter of thickness constant $\beta$ is selected as $-0.0109)$ and for Young's modulus i.e, $E f_{E}(x)=E(1+0.02 \cos (2 \pi x / l)+0.01 \sin (4 \pi x / l))$ and $E f_{E}(x)=E(1-0.02 x / l)^{2}$. Spatial variations of non-uniformities are plotted in Fig. 3 and the natural frequency computations are tabulated in Table 3 together with the relative difference $\%$. 

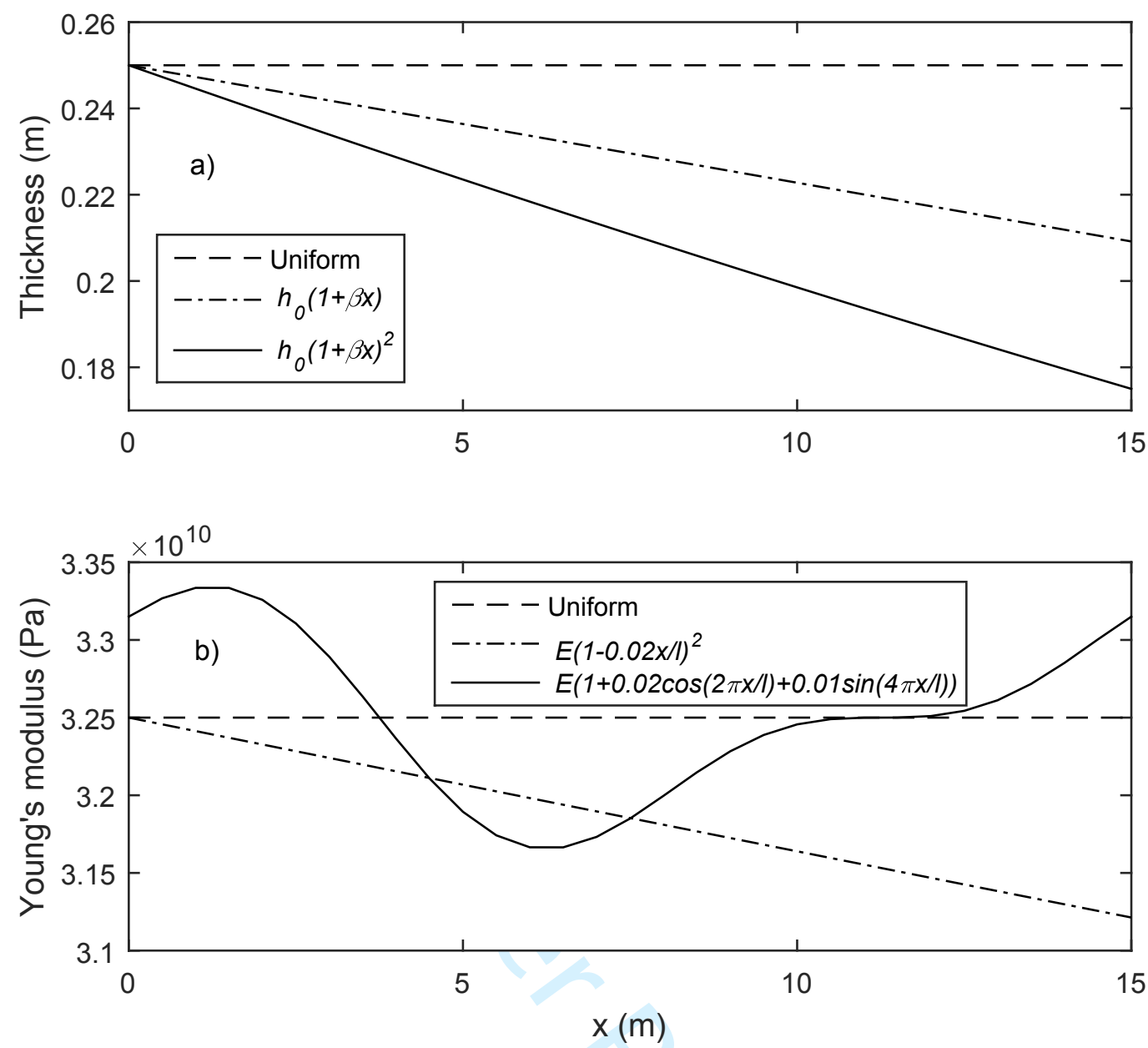

Figure 3. The spatial variations of non-homogeneities a) thickness, b) Young modulus 
Table 3. Natural frequencies of the simply supported non-uniform beam ( $\mathrm{rad} / \mathrm{s})$

\begin{tabular}{|c|c|c|c|c|c|c|c|c|c|c|c|c|c|c|c|c|c|c|c|}
\hline & $\begin{array}{l}\text { Form of } \\
\text { thickness } \\
\text { and } \\
\text { Young's } \\
\text { modulus }\end{array}$ & \multicolumn{3}{|c|}{$\begin{array}{c}h(x)=h_{0}(1+\beta x)^{2} \\
E(x)=E\end{array}$} & \multicolumn{3}{|c|}{$\begin{array}{c}h(x)=h_{0} \\
E(x)=E\left(\begin{array}{l}1+0.02 \cos (2 \pi x / l) \\
+0.01 \sin (4 \pi x / l)\end{array}\right)\end{array}$} & \multicolumn{3}{|c|}{$\begin{array}{c}h(x)=h_{0}(1+\beta x)^{2} \\
E(x)=E\left(\begin{array}{l}1+0.02 \cos (2 \pi x / l) \\
+0.01 \sin (4 \pi x / l)\end{array}\right)\end{array}$} & \multicolumn{3}{|c|}{$\begin{array}{c}h(x)=h_{0}(1+\beta x) \\
E(x)=E\left(\begin{array}{l}1+0.02 \cos (2 \pi x / l) \\
+0.01 \sin (4 \pi x / l)\end{array}\right)\end{array}$} & \multicolumn{3}{|c|}{$\begin{array}{c}h(x)=h_{0}(1+\beta x)^{2} \\
E(x)=E(1-0.02 x / l)^{2}\end{array}$} & \multicolumn{3}{|c|}{$\begin{array}{c}h(x)=h_{0}(1+\beta x) \\
E(x)=E(1-0.02 x / l)^{2}\end{array}$} \\
\hline $\begin{array}{l}10 \\
11 \\
12\end{array}$ & $\begin{array}{l}\text { Mode } \\
\text { Seq. }\end{array}$ & $\begin{array}{c}\text { DSC } \\
\mathbf{M}+\mathbf{1}=\mathbf{3 1}\end{array}$ & $\begin{array}{c}\text { FEM } \\
\mathbf{N}=\mathbf{2 3 0}\end{array}$ & $\begin{array}{l}\text { Rel. } \\
\text { Diff. } \\
\%\end{array}$ & $\begin{array}{c}\text { DSC } \\
\mathbf{M}+\mathbf{1}=\mathbf{3 1}\end{array}$ & $\begin{array}{c}\text { FEM } \\
\mathbf{N}=\mathbf{2 3 0}\end{array}$ & $\begin{array}{l}\text { Rel. } \\
\text { Diff. } \\
\%\end{array}$ & $\begin{array}{c}\mathrm{DSC} \\
\mathrm{M}+\mathbf{1}=\mathbf{3 1}\end{array}$ & $\begin{array}{c}\text { FEM } \\
\mathrm{N}=\mathbf{2 3 0}\end{array}$ & $\begin{array}{c}\text { Rel. } \\
\text { Diff. } \\
\%\end{array}$ & $\begin{array}{c}\text { DSC } \\
\mathbf{M}+\mathbf{1}=\mathbf{3 1}\end{array}$ & $\begin{array}{c}\text { FEM } \\
\mathbf{N}=\mathbf{2 3 0}\end{array}$ & $\begin{array}{c}\text { Rel. } \\
\text { Diff. } \\
\%\end{array}$ & $\begin{array}{c}\text { DSC } \\
\mathbf{M}+\mathbf{1}=\mathbf{3 1}\end{array}$ & $\begin{array}{c}\text { FEM } \\
\mathbf{N}=\mathbf{2 3 0}\end{array}$ & $\begin{array}{c}\text { Rel. } \\
\text { Diff. } \\
\%\end{array}$ & $\begin{array}{c}\text { DSC } \\
\mathbf{M}+\mathbf{1}=\mathbf{3 1}\end{array}$ & $\begin{array}{c}\text { FEM } \\
\mathbf{N}=\mathbf{2 3 0}\end{array}$ & $\begin{array}{c}\text { Rel. } \\
\text { Diff. } \\
\%\end{array}$ \\
\hline 13 & 1 & 9.573 & 9.535 & 0.399 & 10.861 & 11.356 & -4.354 & 9.143 & 9.489 & -3.642 & 10.024 & 10.402 & -3.633 & 9.458 & 9.433 & 0.262 & 10.399 & 10.346 & 0.516 \\
\hline 14 & 2 & 38.669 & 38.353 & 0.823 & 45.631 & 45.652 & -0.047 & 38.444 & 38.320 & 0.323 & 41.867 & 41.844 & 0.055 & 38.285 & 37.959 & 0.859 & 41.581 & 41.438 & 0.345 \\
\hline 15 & 3 & 86.644 & 86.254 & 0.453 & 102.727 & 102.719 & 0.008 & 86.774 & 86.259 & 0.597 & 94.406 & & 0.245 & 85.774 & 85.367 & 0.477 & 93.386 & 93.219 & 0.179 \\
\hline 6 & 4 & 153.716 & 153.292 & 0.277 & 182.618 & 182.611 & 0.004 & 153.786 & 153.283 & 0.328 & 167.607 & 167.395 & 0.126 & 152.158 & 151.713 & 0.293 & 165.883 & 165.705 & 0.107 \\
\hline & 5 & 239.916 & 239.474 & 0.184 & 285.337 & 285.329 & 003 & 239.960 & 239.453 & 0.212 & 261.745 & & 0.080 & 237.470 & 237.007 & 0.195 & 259.082 & 258.899 & 0.070 \\
\hline & 6 & 345.253 & 344.805 & 0.130 & 410.883 & 410.873 & 0.002 & 345.277 & 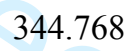 & 0.148 & 376.803 & & 0.055 & 341.722 & 341.250 & 0.138 & 372.986 & 372.802 & 0.049 \\
\hline 0 & 7 & 469.733 & 469.283 & 0.096 & 559.254 & 559.244 & 0.002 & 469.736 & 469.230 & 0.108 & 512.780 & 512.576 & 0.040 & 464.917 & 464.444 & 0.102 & 507.597 & 507.413 & 0.036 \\
\hline 21 & 8 & 613.357 & 612.911 & 0.073 & 730.452 & 730.441 & 0.001 & 613.339 & 612.838 & 0.082 & 669.677 & 669.476 & 0.030 & 607.059 & 606.589 & 0.077 & 662.915 & 662.734 & 0.027 \\
\hline 22 & 9 & 776.127 & 775.688 & 0.057 & 924.475 & 924.464 & 0.001 & 776.085 & 775.593 & 0.063 & 847.492 & 847.296 & 0.023 & 768.149 & 767.686 & 0.060 & 838.941 & 838.763 & 0.021 \\
\hline 23 & 10 & 958.043 & 957.614 & 0.045 & 1141.325 & 1141.313 & 0.001 & 957.977 & 957.496 & 0.050 & 1046.226 & 1046.035 & 0.018 & 948.187 & 947.735 & 0.048 & 1035.674 & 1035.502 & 0.017 \\
\hline
\end{tabular}


As inferred from Table 3, for different non-uniform structures, the DSC and FEM results are not exactly the same but are very consistent with each other. Average computational time is $2.87 \mathrm{~s}$ and $0.36 \mathrm{~s}$ for FEM and the DSC, respectively. Besides, the consistency of the methods reduces for the more complex forms of Young's modulus and thickness. Considering both the relative difference and the computational time, the DSC even with a very small number of discretization points may represent non-uniform structures well and thus reliably used in further complex structures.

\subsection{Stochastic analysis}

In this part of the study, the effects of the geometrical and material variabilities on the natural frequencies are investigated using the DSC and PC expansion (DSC-PCE). In this manner, the beam thickness, Young's Modulus and specific volume vary globally with a normal distribution, i.e. they are uncertain variables but their distributions are known. In the analyses, the standard deviations of the uncertain variables are $5 \%$ of their mean values given in Table 1. Seven uncertainty cases are considered for the uniform and non-uniform beams as shown in Table 4. The analysis starts by solving Eq. (21) eight times for the determination of each coefficient given in Eq. (19). Then, the distribution functions of the natural frequencies are determined using these coefficients with 10000 samples noting that $\omega_{n}=\sqrt{\lambda_{n}}$. In Fig. 4, probability distribution functions of the non-dimensional natural frequency ratio, $\left.\left(\omega_{i}-\mathrm{E}\left[\omega_{i}\right]\right) / \omega_{i}^{\text {uniform }}\right)$, are compared with those obtained by Monte Carlo (MC) simulations performed on the DSC models. Here $\mathrm{E}\left[\omega_{i}\right]$ denotes the mean value of the $i$ th mode. Since each of the probability distribution functions of the non-dimensional natural frequency ratio is the same for all $i=1,2, \ldots 10$, the probability distribution functions are represented here by a single figure. Note that, 10000 samples of uncertain variables are also used in $\mathrm{MC}$ simulations. 
Table 4. Uncertainty cases

\begin{tabular}{|c|c|c|c|}
\hline $\begin{array}{l}\text { Non- } \\
\text { uniformity }\end{array}$ & $\begin{array}{l}\text { Form of the thickness, } \\
\qquad h(x)\end{array}$ & $\begin{array}{l}\text { Form of Young's } \\
\text { modulus, } E(x)\end{array}$ & $\begin{array}{c}\text { Uncertain } \\
\text { parameters: } E\left(\vartheta_{1}\right), \\
h\left(\vartheta_{2}\right), r\left(\vartheta_{3}\right)\end{array}$ \\
\hline Uniform & $h_{0}$ & $E$ & Case 1 \\
\hline \multirow{5}{*}{ Non-uniform } & $\begin{array}{c}h_{0}(1+\beta x)^{2} \\
h_{0}\end{array}$ & $\begin{array}{c}E \\
E\left(\begin{array}{l}1+0.02 \cos (2 \pi x / l) \\
+0.01 \sin (4 \pi x / l)\end{array}\right)\end{array}$ & $\begin{array}{l}\text { Case } 2 \\
\text { Case } 3\end{array}$ \\
\hline & $h_{0}(1+\beta x)^{2}$ & $E\left(\begin{array}{l}1+0.02 \cos (2 \pi x / l) \\
+0.01 \sin (4 \pi x / l)\end{array}\right)$ & Case 4 \\
\hline & $h_{0}(1+\beta x)$ & $E\left(\begin{array}{l}1+0.02 \cos (2 \pi x / l) \\
+0.01 \sin (4 \pi x / l)\end{array}\right)$ & Case 5 \\
\hline & $h_{0}(1+\beta x)^{2}$ & $E(1-0.02 x / l)^{2}$ & Case 6 \\
\hline & $h_{0}(1+\beta x)$ & $E(1-0.02 x / l)^{2}$ & Case 7 \\
\hline
\end{tabular}
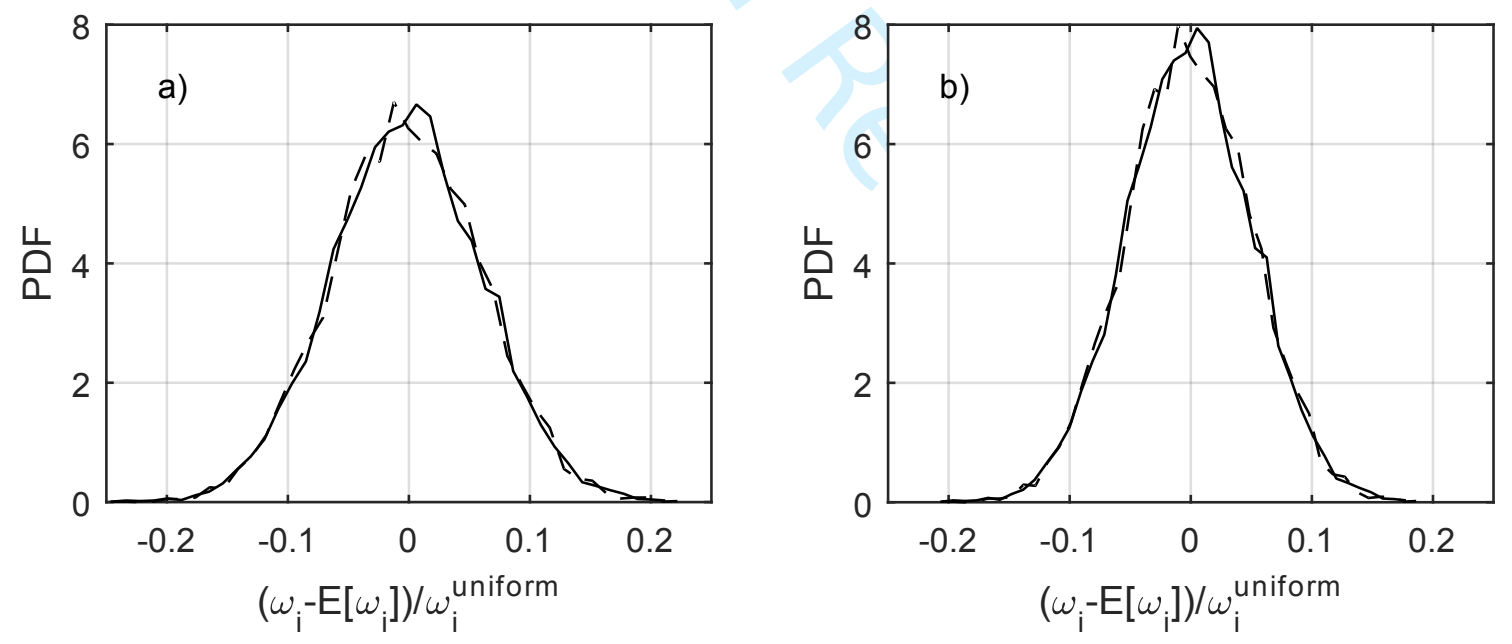

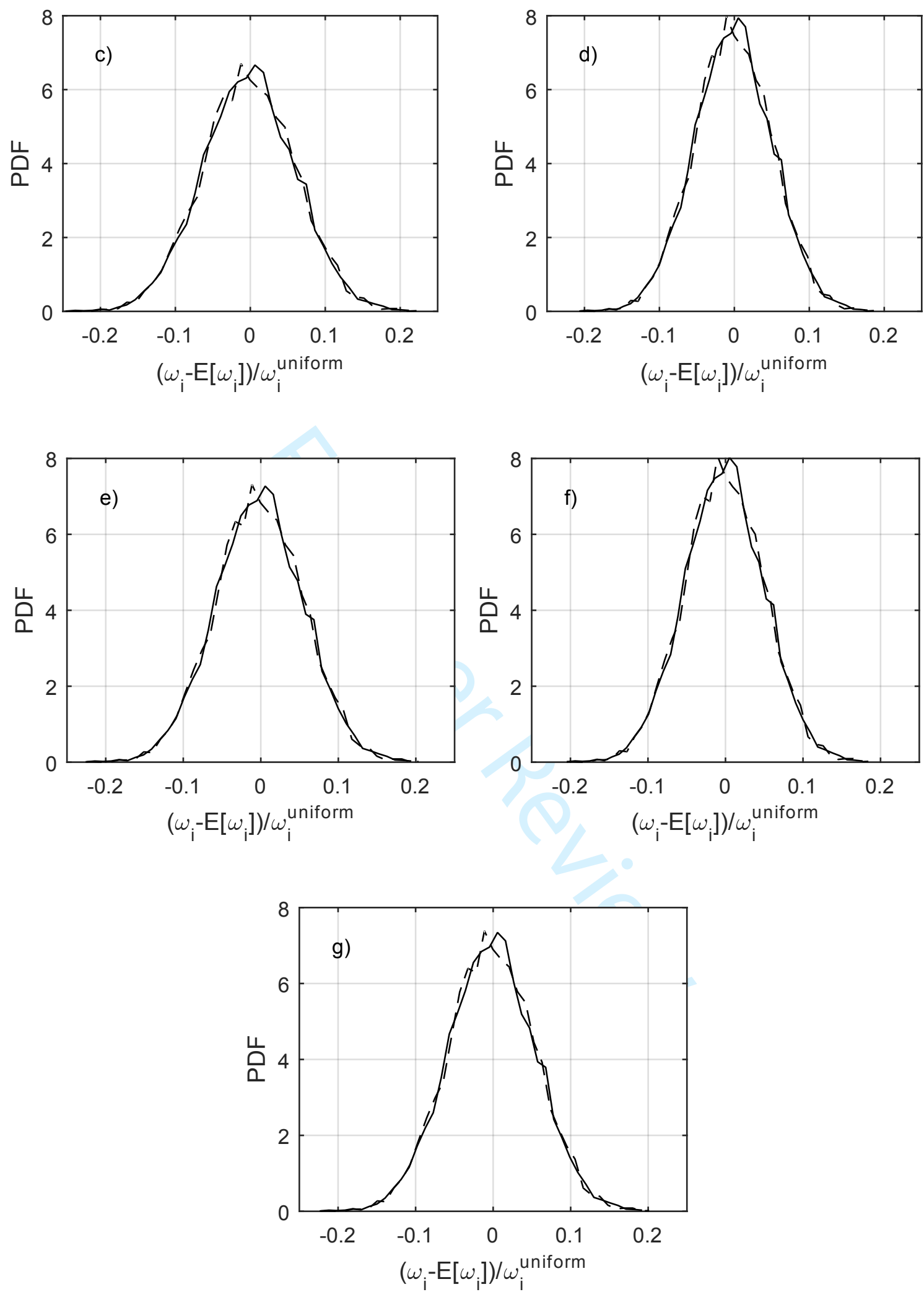

Figure 4. Probability distribution functions of non-dimensional natural frequency ratios for uncertain a) Case 1, b) Case 2, c) Case 3, d) Case 4, e) Case 5, f) Case 6, g) Case 7 (solid line: PCE, dash line: Monte Carlo) 
It is seen from Fig. 4 that the predictions of the DSC-PCE are quite consistent with those of $\mathrm{MC}$ simulations for all cases. Besides, average computation time for the DSC-PCE is $3.72 \mathrm{~s}$ whereas it is 8.52 for Monte Carlo simulation. The results show that DSC-PCE method is very accurate and efficient and therefore can be reliably used for uncertainty analysis of nonuniform structures.

\section{Conclusions}

In this study, a combination of Discrete Singular Convolution (DSC) and Polynomial Chaos Expansion (PCE) is introduced for non-uniform beams having geometrical and material variabilities. The DSC method is applied to model the non-uniform beam having local changes in the Young's Modulus and thickness along its length. The PCE is utilized to handle variabilities simulating uncertainty in a global manner. The DSC-PCE method is verified for uniform and non-uniform beams using the finite element method and Monte Carlo simulations. It is shown that the DSC method is very straightforward in modelling nonuniformity along the spatial domain, and it is very accurate even with a relatively small number of discretization points compared to the finite element method. It is also shown that the combined DSC-PCE methodology is very efficient in computational cost and it quantifies quite well the uncertainty due to the geometrical and material parameters. The study promises that the present methodology is worth further development in order to apply it to more complex systems, especially for mid and high frequency analysis.

\section{Acknowledgments}

This study is supported by "The Scientific and Technological Research Council of Turkey, TUBITAK" in the frame of TUBITAK 2219. 


\section{Declaration of Conflicting Interests}

The Authors declare that there is no conflict of interest.

\section{References}

Akgöz B and Civalek Ö (2013) Longitudinal vibration analysis of strain gradient bars made of functionally graded materials (FGM). Composites Part B: Engineering 55. Elsevier: 263-268. DOI: 10.1016/j.compositesb.2013.06.035.

Alshorbagy AE, Eltaher MA and Mahmoud FF (2011) Free vibration characteristics of a functionally graded beam by finite element method. Applied Mathematical Modelling 35(1). Elsevier: 412-425. DOI: 10.1016/j.apm.2010.07.006.

Bailey CD (1978) Direct analytical solutions to non-uniform beam problems. Journal of Sound and Vibration 56(4). Academic Press: 501-507. DOI: 10.1016/0022460X(78)90292-4.

Baltacıŏlu AK, Akgöz B and Civalek Ö (2010) Nonlinear static response of laminated composite plates by discrete singular convolution method. Composite Structures 93(1): 153-161. DOI: 10.1016/j.compstruct.2010.06.005.

Baltacıŏlu AK, Civalek Ö, Akgöz B, et al. (2011) Large deflection analysis of laminated composite plates resting on nonlinear elastic foundations by the method of discrete singular convolution. International Journal of Pressure Vessels and Piping 88(8-9): 290-300. DOI: 10.1016/j.ijpvp.2011.06.004.

Civalek Ö (2007) Three-dimensional vibration, buckling and bending analyses of thick rectangular plates based on discrete singular convolution method. International Journal of Mechanical Sciences 49(6). Pergamon: 752-765. DOI:

10.1016/J.IJMECSCI.2006.10.002.

Civalek Ö (2008a) Free vibration of curvilinear membranes by eight-noded Discrete Singular 
Convolution (DSC). International Journal of Science \& Technology 3(2): 165-171. DOI: 10.05.2008.

Civalek Ö (2008b) Vibration analysis of membranes with arbitrary shapes using discrete singular convolution. CMES - Computer Modeling in Engineering and Sciences 31(1): 25-36. DOI: 10.1525/sp.2007.54.1.23.

Civalek Ö (2009) Eigenvalues of membranes having skew and rhombic geometry using discrete singular convolution algorithm. Communications in Nonlinear Science and Numerical Simulation 14(11). Elsevier: 4003-4009. DOI: 10.1016/j.cnsns.2008.08.010.

Civalek Ö (2013) Nonlinear dynamic response of laminated plates resting on nonlinear elastic foundations by the discrete singular convolution-differential quadrature coupled approaches. Composites Part B: Engineering 50: 171-179. DOI:

10.1016/j.compositesb.2013.01.027.

Civalek Ö (2017) Free vibration of carbon nanotubes reinforced (CNTR) and functionally graded shells and plates based on FSDT via discrete singular convolution method. Composites Part B: Engineering 111: 45-59. DOI: 10.1016/j.compositesb.2016.11.030. Elishakoff I and Johnson V (2005) Apparently the first closed-form solution of vibrating inhomogeneous beam with a tip mass. Journal of Sound and Vibration 286(4-5). Academic Press: 1057-1066. DOI: 10.1016/j.jsv.2005.01.050.

Ersoy H, Özpolat L and Civalek Ö (2009) Free vibration of circular and annular membranes with varying density by the method of discrete singular convolution. Structural Engineering and Mechanics 32(5). Techno-Press: 621-634. DOI: 10.12989/sem.2009.32.5.621.

Ersoy H, Civalek Ö and Özpolat L (2010) Free vibration analysis of rectangular membranes with variable density using the discrete singular convolution approach. Asian Journal of Civil Engineering (Building And Housing) 11(1): 83-94. 
Evans DH (1972) An application of numerical integration techniques to statistical tolerancing, III-general distributions. Technometrics 14(1). Taylor \& Francis Group: 23-35. DOI: 10.1080/00401706.1972.10488880.

Evans M and Swartz T (2000) Approximating Integrals via Monte Carlo and Deterministic Methods. Oxford: Oxford University Press.

Falsone G and Impollonia N (2004) About the accuracy of a novel response surface method for the analysis of finite element modeled uncertain structures. In: Probabilistic Engineering Mechanics, 1 January 2004, pp. 53-63. Elsevier. DOI:

10.1016/j.probengmech.2003.11.005.

Ghanem RG and Spanos PD (2003) Stochastic Finite Elements: A Spectral Approach. New York: Dover Publications.

Gürses M, Civalek Ö, Korkmaz AK, et al. (2009) Free vibration analysis of symmetric laminated skew plates by discrete singular convolution technique based on first-order shear deformation theory. International Journal for Numerical Methods in Engineering 79(3). John Wiley \& Sons, Ltd: 290-313. DOI: 10.1002/nme.2553.

Gürses M, Akgöz B and Civalek Ö (2012) Mathematical modeling of vibration problem of nano-sized annular sector plates using the nonlocal continuum theory via eight-node discrete singular convolution transformation. Applied Mathematics and Computation 219(6): 3226-3240. DOI: 10.1016/j.amc.2012.09.062.

Hohenbichler M and Rackwitz R (1989) Improvement of second-order reliability estimates by importance sampling. Journal of Engineering Mechanics 114(12): 2195-2199. DOI: 10.1061/(ASCE)0733-9399(1988)114:12(2195).

Impollonia N and Sofi A (2003) A response surface approach for the static analysis of stochastic structures with geometrical nonlinearities. Computer Methods in Applied Mechanics and Engineering 192(37-38). Elsevier: 4109-4129. DOI: 10.1016/S0045- 
7825(03)00379-7.

Kara M and Seçgin A (2019) Discrete singular convolution method for one-dimensional vibration and acoustics problems with impedance boundaries. Journal of Sound and Vibration 446. Academic Press: 22-36. DOI: 10.1016/j.jsv.2019.01.028.

Keane AJ and Price WC (1997) Statistical Energy Analysis. An Overview with Applications in Structural Dynamics. Keane A and Price W (eds). Cambridge: Cambridge University Press.

Kompella MS and Bernhard RJ (1993) Measurement of the statistical variation of structuralacoustic characteristics of automotive vehicles. In: SAE Technical Papers, 1993. SAE International. DOI: $10.4271 / 931272$.

Korayem MH and Homayooni A (2017) The size-dependent analysis of multilayer microcantilever plate with piezoelectric layer incorporated voltage effect based on a modified couple stress theory. European Journal of Mechanics, A/Solids 61. Elsevier Ltd: 59-72. DOI: 10.1016/j.euromechsol.2016.08.013.

Korayem MH, Sadeghzadeh S and Rahneshin V (2012) A new multiscale methodology for modeling of single and multi-body solid structures. Computational Materials Science 63. Elsevier: 1-11. DOI: 10.1016/j.commatsci.2012.05.059.

Lucor D, Su CH and Karniadakis GE (2004) Generalized polynomial chaos and random oscillators. International Journal for Numerical Methods in Engineering 60(3). WileyBlackwell: 571-596. DOI: 10.1002/nme.976.

Mercan K and Civalek Ö (2016) DSC method for buckling analysis of boron nitride nanotube (BNNT) surrounded by an elastic matrix. Composite Structures 143. Elsevier: 300-309. DOI: 10.1016/j.compstruct.2016.02.040.

Nazemizadeh M and Bakhtiari-Nejad F (2015) A general formulation of quality factor for composite micro/nano beams in the air environment based on the nonlocal elasticity 
theory. Composite Structures 132. Elsevier Ltd: 772-783. DOI:

10.1016/j.compstruct.2015.05.070.

Rahman S and Xu H (2004) A univariate dimension-reduction method for multi-dimensional integration in stochastic mechanics. Probabilistic Engineering Mechanics 19(4): 393408. DOI: 10.1016/j.probengmech.2004.04.003.

Rao SS (2011) Mechanical Vibrations. 5th Ed. New York: Prentice Hall.

Rubinstein RY and Kroese DP (2016) Simulation and the Monte Carlo Method. John Wiley $\&$ Sons.

Sankar B V. (2001) An elasticity solution for functionally graded beams. Composites Science and Technology 61(5). Elsevier: 689-696. DOI: 10.1016/S0266-3538(01)00007-0.

Seçgin A (2013) Modal and response bound predictions of uncertain rectangular composite plates based on an extreme value model. Journal of Sound and Vibration 332(5): 13061323. DOI: 10.1016/j.jsv.2012.09.036.

Seçgin A and Kara M (2018) Vibration bounding of uncertain thin beams by using an extreme value model based on statistical moments. JVC/Journal of Vibration and Control 24(23). SAGE Publications Sage UK: London, England: 5627-5641. DOI: 10.1177/1077546318763203.

Seçgin A and Sarigül AS (2008) Free vibration analysis of symmetrically laminated thin composite plates by using discrete singular convolution (DSC) approach: Algorithm and verification. Journal of Sound and Vibration 315(1-2). Academic Press: 197-211. DOI: 10.1016/j.jsv.2008.01.061.

Seçgin A and Sarigül AS (2009) A novel scheme for the discrete prediction of high-frequency vibration response: Discrete singular convolution-mode superposition approach. Journal of Sound and Vibration 320(4-5). Academic Press: 1004-1022. DOI: 10.1016/j.jsv.2008.08.031. 
Seçgin A, Dunne JF and Zoghaib L (2012) Extreme-value-based statistical bounding of low, mid, and high frequency responses of a forced plate with random boundary conditions. Journal of Vibration and Acoustics 134(2). American Society of Mechanical Engineers: 021003. DOI: $10.1115 / 1.4005019$.

Seo HS and Kwak BM (2002) Efficient statistical tolerance analysis for general distributions using three-point information. International Journal of Production Research 40(4). Taylor \& Francis Group: 931-944. DOI: 10.1080/00207540110095709.

Sepahvand K (2017) Stochastic finite element method for random harmonic analysis of composite plates with uncertain modal damping parameters. Journal of Sound and Vibration 400: 1-12. DOI: 10.1016/j.jsv.2017.04.025.

Sepahvand K, Marburg S and Hardtke H-J (2007) Numerical solution of one-dimensional wave equation with stochastic parameters using generalized polynomial chaos expansion. Journal of Computational Acoustics 15(04): 579-593. DOI: 10.1142/S0218396X07003524.

Sepahvand K, Marburg S and Hardtke H-J (2010) Uncertainty quantification in stochastic systems using polynomial chaos expansion. International Journal of Applied Mechanics 02(02): 305-353. DOI: 10.1142/S1758825110000524.

Shokrollahi M and Zayeri Baghlani Nejad A (2014) Numerical analysis of free longitudinal vibration of nonuniform rods: Discrete Singular Convolution approach. Journal of Engineering Mechanics 140(8): 06014007. DOI: 10.1061/(ASCE)EM.19437889.0000772 .

Tan G, Wang W and Jiao Y (2016) Flexural free vibrations of multistep nonuniform beams. Mathematical Problems in Engineering 2016. Hindawi: 1-12. DOI: $10.1155 / 2016 / 7314280$.

Tan G, Liu Y, Gong Y, et al. (2018) Free Vibration of the Cracked Non-uniform Beam with 
Cross Section Varying as Polynomial Functions. KSCE Journal of Civil Engineering 22(11). Springer Verlag: 4530-4546. DOI: 10.1007/s12205-018-1833-5.

Wei GW (1999) Discrete singular convolution for the solution of the Fokker-Planck equation. The Journal of Chemical Physics 110(18): 8930-8942. DOI: 10.1063/1.478812.

Wei GW (2001a) A new algorithm for solving some mechanical problems. Computer Methods in Applied Mechanics and Engineering 190(15-17): 2017-2030. DOI: 10.1016/S0045-7825(00)00219-X.

Wei GW (2001b) Discrete singular convolution for beam analysis. Engineering Structures 23(9): 1045-1053. DOI: 10.1016/S0141-0296(01)00016-5.

Wei GW (2001c) Vibration analysis by discrete singular convolution. Journal of Sound and Vibration 244(3): 535-553. DOI: 10.1006/jsvi.2000.3507.

Wei GW, Zhao YB and Xiang Y (2001) The determination of natural frequencies of rectangular plates with mixed boundary conditions by discrete singular convolution. International Journal of Mechanical Sciences 43(8). Pergamon: 1731-1746. DOI: 10.1016/S0020-7403(01)00021-2.

Wei GW, Zhao YB and Xiang Y (2002a) A novel approach for the analysis of high-frequency vibrations. Journal of Sound and Vibration 257(2): 207-246. DOI: 10.1006/jsvi.5055.

Wei GW, Zhao YB and Xiang Y (2002b) Discrete singular convolution and its application to the analysis of plates with internal supports. Part 1: Theory and algorithm. International Journal for Numerical Methods in Engineering 55(8). John Wiley \& Sons, Ltd.: 913946. DOI: $10.1002 / \mathrm{nme} .526$.

Zhao S, Wei GW and Xiang Y (2005) DSC analysis of free-edged beams by an iteratively matched boundary method. Journal of Sound and Vibration 284(1-2): 487-493. DOI: 10.1016/j.jsv.2004.08.037. 
Table 1. Material and geometrical properties of the beam

\begin{tabular}{lc}
\hline Property (Unit) & Value \\
\hline Young' modulus $(\mathrm{Pa})$ & $3.25 \mathrm{E}+10$ \\
Density $\left(\mathrm{kgm}^{-3}\right)$ & 2500 \\
Thickness at $x=0(\mathrm{~m})$ & 0.25 \\
Width $(\mathrm{m})$ & 0.3 \\
Length $(\mathrm{m})$ & 15 \\
\hline
\end{tabular}

14
15 
Table 2. Natural frequencies of the simply supported uniform beam ( $\mathrm{rad} / \mathrm{s})$

\begin{tabular}{c|cccccccc}
\hline $\begin{array}{c}\text { Mode } \\
\text { Seq. }\end{array}$ & $\begin{array}{c}\text { Analy. } \\
(\text { Rao, 2011) }\end{array}$ & $\begin{array}{c}\text { DSC } \\
\text { N=11 }\end{array}$ & $\begin{array}{c}\text { DSC } \\
\text { N=21 }\end{array}$ & $\begin{array}{c}\text { DSC } \\
\text { N=31 }\end{array}$ & $\begin{array}{c}\text { FEM } \\
\text { N=20 }\end{array}$ & $\begin{array}{c}\text { FEM } \\
\text { N=60 }\end{array}$ & $\begin{array}{c}\text { FEM } \\
\text { N=120 }\end{array}$ & $\begin{array}{c}\text { FEM } \\
\text { N=230 }\end{array}$ \\
\hline 1 & 11.414 & 11.411 & 11.414 & 11.414 & 11.414 & 11.414 & 11.414 & 11.414 \\
2 & 45.656 & 45.667 & 45.656 & 45.656 & 45.656 & 45.656 & 45.656 & 45.656 \\
3 & 102.726 & 102.828 & 102.726 & 102.726 & 102.730 & 102.726 & 102.726 & 102.726 \\
4 & 182.624 & 183.501 & 182.624 & 182.624 & 182.644 & 182.624 & 182.624 & 182.624 \\
5 & 285.350 & 290.841 & 285.350 & 285.350 & 285.424 & 285.351 & 285.350 & 285.350 \\
6 & 410.904 & 434.686 & 410.904 & 410.904 & 411.124 & 410.907 & 410.905 & 410.904 \\
7 & 559.287 & 627.888 & 559.287 & 559.287 & 559.835 & 559.294 & 559.287 & 559.287 \\
8 & 730.497 & 858.099 & 730.497 & 730.497 & 731.707 & 730.512 & 730.498 & 730.497 \\
9 & 924.535 & 1059.665 & 924.538 & 924.535 & 926.960 & 924.566 & 924.537 & 924.535 \\
10 & 1141.401 & & 1141.427 & 1141.401 & 1145.906 & 1141.460 & 1141.405 & 1141.401 \\
\hline & & & & Error & $\mathbf{0}$ & & & \\
\hline 1 & - & $-2.78 \mathrm{E}-02$ & $-3.55 \mathrm{E}-05$ & $-4.39 \mathrm{E}-07$ & $4.22 \mathrm{E}-05$ & $4.92 \mathrm{E}-07$ & $2.80 \mathrm{E}-06$ & $8.27 \mathrm{E}-06$ \\
2 & - & $2.35 \mathrm{E}-02$ & $2.16 \mathrm{E}-06$ & $2.71 \mathrm{E}-08$ & $6.75 \mathrm{E}-04$ & $8.35 \mathrm{E}-06$ & $5.94 \mathrm{E}-07$ & $1.01 \mathrm{E}-06$ \\
3 & - & $9.94 \mathrm{E}-02$ & $-4.05 \mathrm{E}-07$ & $-5.27 \mathrm{E}-09$ & $3.40 \mathrm{E}-03$ & $4.22 \mathrm{E}-05$ & $2.70 \mathrm{E}-06$ & $5.67 \mathrm{E}-07$ \\
4 & - & $4.80 \mathrm{E}-01$ & $1.20 \mathrm{E}-07$ & $1.62 \mathrm{E}-09$ & $1.07 \mathrm{E}-02$ & $1.33 \mathrm{E}-04$ & $8.36 \mathrm{E}-06$ & $8.20 \mathrm{E}-07$ \\
5 & - & $1.92 \mathrm{E}+00$ & $-2.74 \mathrm{E}-08$ & $-6.42 \mathrm{E}-10$ & $2.60 \mathrm{E}-02$ & $3.26 \mathrm{E}-04$ & $2.04 \mathrm{E}-05$ & $1.61 \mathrm{E}-06$ \\
6 & - & $5.79 \mathrm{E}+00$ & $2.57 \mathrm{E}-07$ & $2.98 \mathrm{E}-10$ & $5.34 \mathrm{E}-02$ & $6.75 \mathrm{E}-04$ & $4.22 \mathrm{E}-05$ & $3.14 \mathrm{E}-06$ \\
7 & - & $1.23 \mathrm{E}+01$ & $3.01 \mathrm{E}-06$ & $-1.51 \mathrm{E}-10$ & $9.81 \mathrm{E}-02$ & $1.25 \mathrm{E}-03$ & $7.83 \mathrm{E}-05$ & $5.82 \mathrm{E}-06$ \\
8 & - & $1.75 \mathrm{E}+01$ & $3.26 \mathrm{E}-05$ & $8.31 \mathrm{E}-11$ & $1.66 \mathrm{E}-01$ & $2.13 \mathrm{E}-03$ & $1.33 \mathrm{E}-04$ & $9.90 \mathrm{E}-06$ \\
9 & - & $1.46 \mathrm{E}+01$ & $2.97 \mathrm{E}-04$ & $-4.72 \mathrm{E}-11$ & $2.62 \mathrm{E}-01$ & $3.40 \mathrm{E}-03$ & $2.14 \mathrm{E}-04$ & $1.59 \mathrm{E}-05$ \\
10 & - & & $2.24 \mathrm{E}-03$ & $2.80 \mathrm{E}-11$ & $3.95 \mathrm{E}-01$ & $5.18 \mathrm{E}-03$ & $3.26 \mathrm{E}-04$ & $2.42 \mathrm{E}-05$ \\
\hline
\end{tabular}


Table 3. Natural frequencies of the simply supported non-uniform beam ( $\mathrm{rad} / \mathrm{s})$

\begin{tabular}{|c|c|c|c|c|c|c|c|c|c|c|c|c|c|c|c|c|c|c|c|}
\hline & $\begin{array}{l}\text { Form of } \\
\text { thickness } \\
\text { and } \\
\text { Young's } \\
\text { modulus }\end{array}$ & \multicolumn{3}{|c|}{$\begin{array}{c}h(x)=h_{0}(1+\beta x)^{2} \\
E(x)=E\end{array}$} & \multicolumn{3}{|c|}{$\begin{array}{c}h(x)=h_{0} \\
E(x)=E\left(\begin{array}{l}1+0.02 \cos (2 \pi x / l) \\
+0.01 \sin (4 \pi x / l)\end{array}\right)\end{array}$} & \multicolumn{3}{|c|}{$\begin{array}{c}h(x)=h_{0}(1+\beta x)^{2} \\
E(x)=E\left(\begin{array}{l}1+0.02 \cos (2 \pi x / l) \\
+0.01 \sin (4 \pi x / l)\end{array}\right)\end{array}$} & \multicolumn{3}{|c|}{$\begin{array}{c}h(x)=h_{0}(1+\beta x) \\
E(x)=E\left(\begin{array}{l}1+0.02 \cos (2 \pi x / l) \\
+0.01 \sin (4 \pi x / l)\end{array}\right)\end{array}$} & \multicolumn{3}{|c|}{$\begin{array}{c}h(x)=h_{0}(1+\beta x)^{2} \\
E(x)=E(1-0.02 x / l)^{2}\end{array}$} & \multicolumn{3}{|c|}{$\begin{array}{c}h(x)=h_{0}(1+\beta x) \\
E(x)=E(1-0.02 x / l)^{2}\end{array}$} \\
\hline 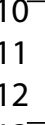 & $\begin{array}{l}\text { Mode } \\
\text { Seq. }\end{array}$ & $\begin{array}{c}\text { DSC } \\
\mathbf{M}+\mathbf{1}=\mathbf{3 1}\end{array}$ & $\begin{array}{c}\text { FEM } \\
\mathbf{N}=\mathbf{2 3 0}\end{array}$ & $\begin{array}{c}\text { Rel. } \\
\text { Diff. } \\
\%\end{array}$ & $\begin{array}{c}\text { DSC } \\
\mathbf{M}+\mathbf{1}=\mathbf{3 1}\end{array}$ & $\begin{array}{c}\text { FEM } \\
\mathbf{N}=\mathbf{2 3 0}\end{array}$ & $\begin{array}{c}\text { Rel. } \\
\text { Diff. } \\
\%\end{array}$ & $\begin{array}{c}\text { DSC } \\
\mathrm{M}+\mathbf{1}=\mathbf{3 1}\end{array}$ & $\begin{array}{c}\text { FEM } \\
\mathrm{N}=\mathbf{2 3 0}\end{array}$ & $\begin{array}{c}\text { Rel. } \\
\text { Diff. } \\
\%\end{array}$ & $\begin{array}{c}\text { DSC } \\
\mathbf{M}+\mathbf{1}=\mathbf{3 1}\end{array}$ & $\begin{array}{c}\text { FEM } \\
\mathbf{N}=\mathbf{2 3 0}\end{array}$ & $\begin{array}{c}\text { Rel. } \\
\text { Diff. } \\
\%\end{array}$ & $\begin{array}{c}\text { DSC } \\
\mathbf{M}+\mathbf{1}=\mathbf{3 1}\end{array}$ & $\begin{array}{c}\text { FEM } \\
\mathbf{N}=\mathbf{2 3 0}\end{array}$ & $\begin{array}{c}\text { Rel. } \\
\text { Diff. } \\
\%\end{array}$ & $\begin{array}{c}\text { DSC } \\
\mathbf{M}+\mathbf{1}=\mathbf{3 1}\end{array}$ & $\begin{array}{c}\text { FEM } \\
\mathbf{N}=\mathbf{2 3 0}\end{array}$ & $\begin{array}{c}\text { Rel. } \\
\text { Diff. } \\
\%\end{array}$ \\
\hline & 1 & 9.573 & 9.535 & 0.399 & 10.861 & 11.356 & -4.354 & 9.143 & 9.489 & -3.642 & 10.024 & 10.402 & -3.633 & 9.458 & 9.433 & 0.262 & 10.399 & 10.346 & 0.516 \\
\hline & 2 & 38.669 & 38.353 & 0.823 & 45.631 & 45.652 & -0.047 & 38.444 & 38.320 & 0.323 & 41.867 & 41.844 & 0.055 & 38.285 & 37.959 & 0.859 & 41.581 & 41.438 & 0.345 \\
\hline & 3 & 86.644 & 86.254 & 0.453 & 102.727 & 102.719 & 0.008 & 86.774 & & 0.597 & & & 0.245 & 85.774 & 85.367 & 0.477 & 93.386 & 219 & 0.179 \\
\hline & 4 & 153.716 & 153.292 & 0.277 & 182.618 & 182.611 & 0.004 & 153.786 & 153.283 & 0.328 & 167.607 & 167.395 & 0.126 & 152.158 & 151.713 & 0.293 & 165.883 & 165.705 & 0.107 \\
\hline & 5 & 239.916 & 239.474 & 0.184 & 285.337 & 285.329 & 0.003 & 239.960 & 239.453 & 0.212 & 261.745 & 261.536 & 0.080 & 237.470 & 237.007 & 0.195 & 259.082 & 258.899 & 0.070 \\
\hline & 6 & 345.253 & 344.805 & 0.130 & 410.883 & 410.873 & 0.002 & 345.277 & 214760 & 0.148 & 376.803 & 376.596 & 0.055 & 341.722 & 341.250 & 0.138 & 372.986 & 372.802 & 0.049 \\
\hline & 7 & 469.733 & 469.283 & 0.096 & 559.254 & 559.244 & 0.002 & 469.736 & 469.230 & 0.108 & 512.780 & 512.576 & 0.040 & 464.917 & 464.444 & 0.102 & 507.597 & 507.413 & 0.036 \\
\hline & 8 & 613.357 & 612.911 & 0.073 & 730.452 & 730.441 & 0.001 & 613.339 & 612.838 & 0.082 & 669.677 & 669.476 & 0.030 & 607.059 & 606.589 & 0.077 & 662.915 & 662.734 & 0.027 \\
\hline & 9 & 776.127 & 775.688 & 0.057 & 924.475 & 924.464 & 0.001 & 776.085 & 775.593 & 0.063 & 847.492 & 847.296 & 0.023 & 768.149 & 767.686 & 0.060 & 838.941 & 838.763 & 0.021 \\
\hline & 10 & 958.043 & 957.614 & 0.045 & 1141.325 & 1141.313 & 0.001 & 957.977 & 957.496 & 0.050 & 1046.226 & 1046.035 & 0.018 & 948.187 & 947.735 & 0.048 & 1035.674 & 1035.502 & 0.017 \\
\hline
\end{tabular}


Table 4. Uncertainty cases

\begin{tabular}{|c|c|c|c|}
\hline $\begin{array}{l}\text { Non- } \\
\text { uniformity }\end{array}$ & $\begin{array}{l}\text { Form of the thickness, } \\
\qquad h(x)\end{array}$ & $\begin{array}{l}\text { Form of Young's } \\
\text { modulus, } E(x)\end{array}$ & $\begin{array}{c}\text { Uncertain } \\
\text { parameters: } E\left(\vartheta_{1}\right), \\
h\left(\vartheta_{2}\right), r\left(\vartheta_{3}\right)\end{array}$ \\
\hline Uniform & $h_{0}$ & $E$ & Case 1 \\
\hline \multirow{5}{*}{ Non-uniform } & $\begin{array}{c}h_{0}(1+\beta x)^{2} \\
h_{0}\end{array}$ & $E\left(\begin{array}{c}E \\
1+0.02 \cos (2 \pi x / l) \\
+0.01 \sin (4 \pi x / l)\end{array}\right)$ & $\begin{array}{l}\text { Case } 2 \\
\text { Case } 3\end{array}$ \\
\hline & $h_{0}(1+\beta x)^{2}$ & $E\left(\begin{array}{l}1+0.02 \cos (2 \pi x / l) \\
+0.01 \sin (4 \pi x / l)\end{array}\right)$ & Case 4 \\
\hline & $h_{0}(1+\beta x)$ & $E\left(\begin{array}{l}1+0.02 \cos (2 \pi x / l) \\
+0.01 \sin (4 \pi x / l)\end{array}\right)$ & Case 5 \\
\hline & $h_{0}(1+\beta x)^{2}$ & $E(1-0.02 x / l)^{2}$ & Case 6 \\
\hline & $h_{0}(1+\beta x)$ & $E(1-0.02 x / l)^{2}$ & Case 7 \\
\hline
\end{tabular}




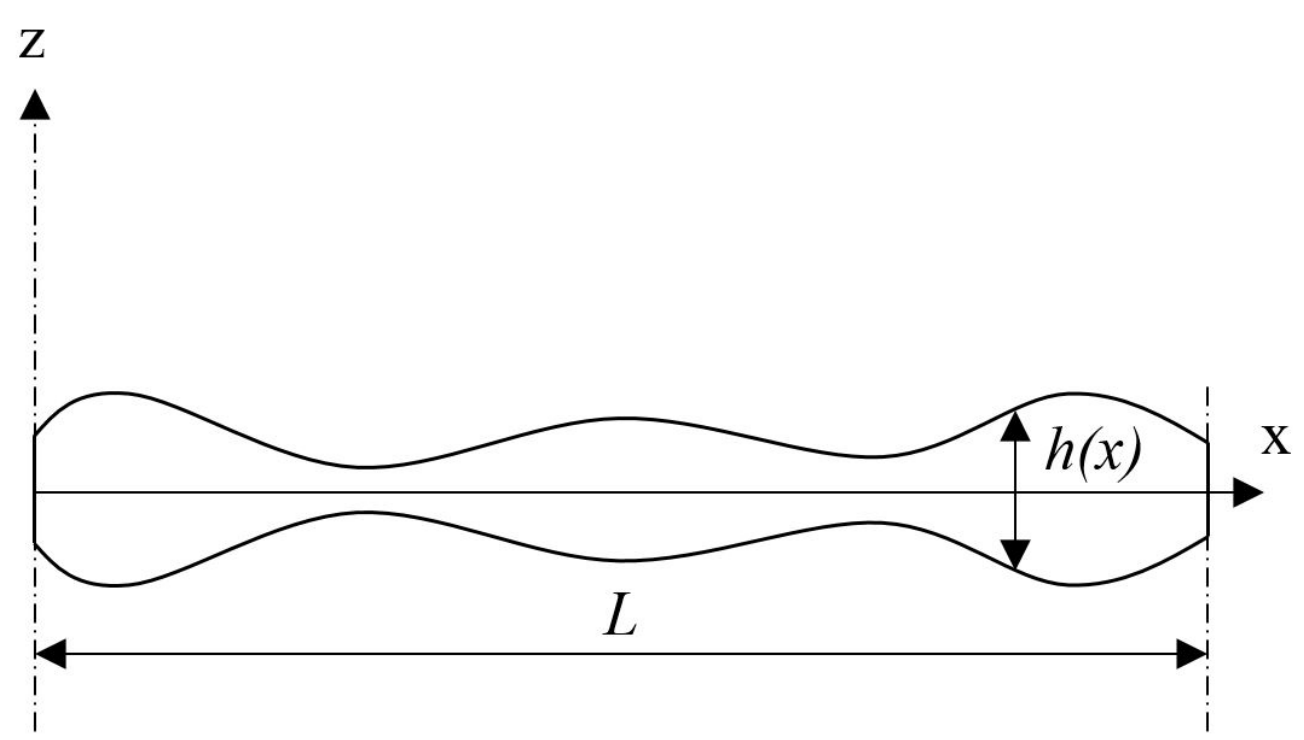

Figure 1. A beam structure with its geometrical parameters

$285 \times 157 \mathrm{~mm}(96 \times 96 \mathrm{DPI})$ 


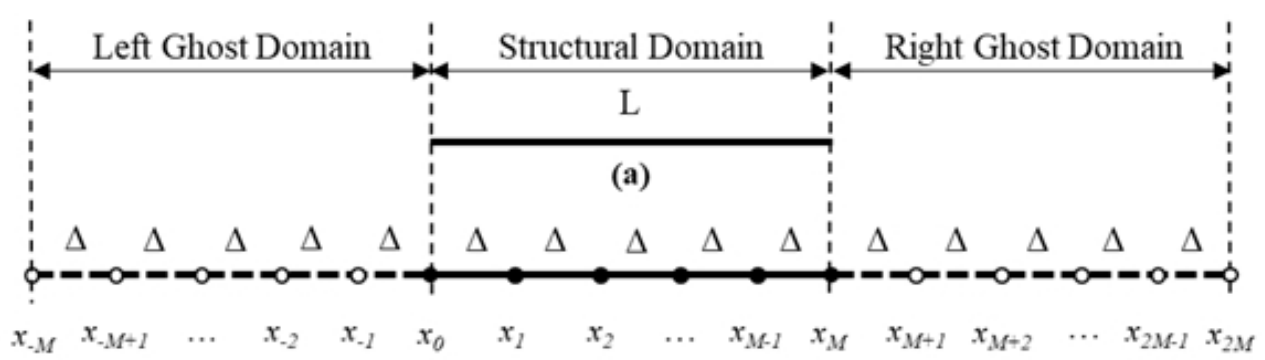

(b)

\section{Figure 2}

$156 \times 60 \mathrm{~mm}(96 \times 96 \mathrm{DPI})$ 

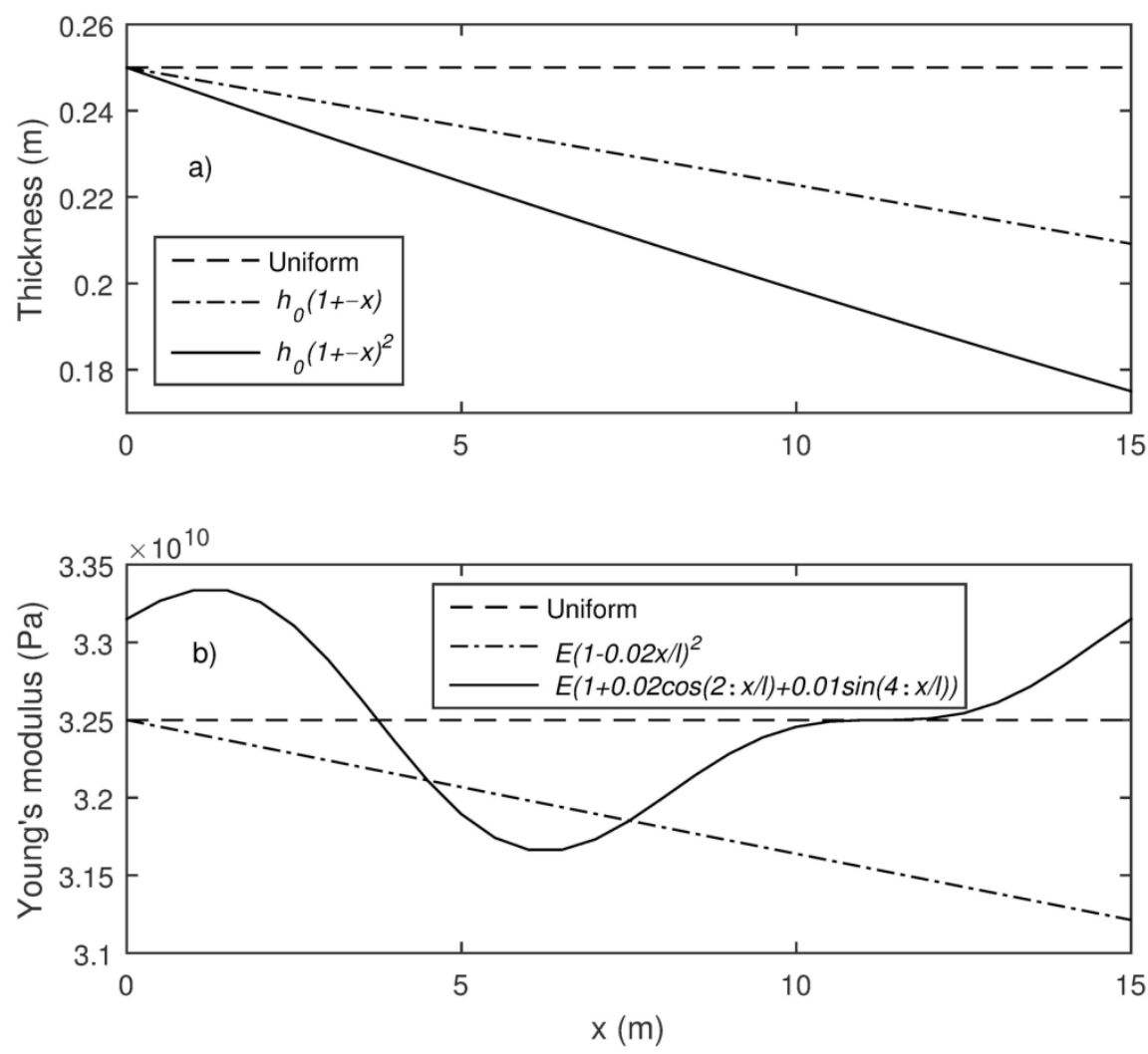

$157 \times 138 \mathrm{~mm}(300 \times 300 \mathrm{DPI})$

http://mc.manuscriptcentral.com/jvc 


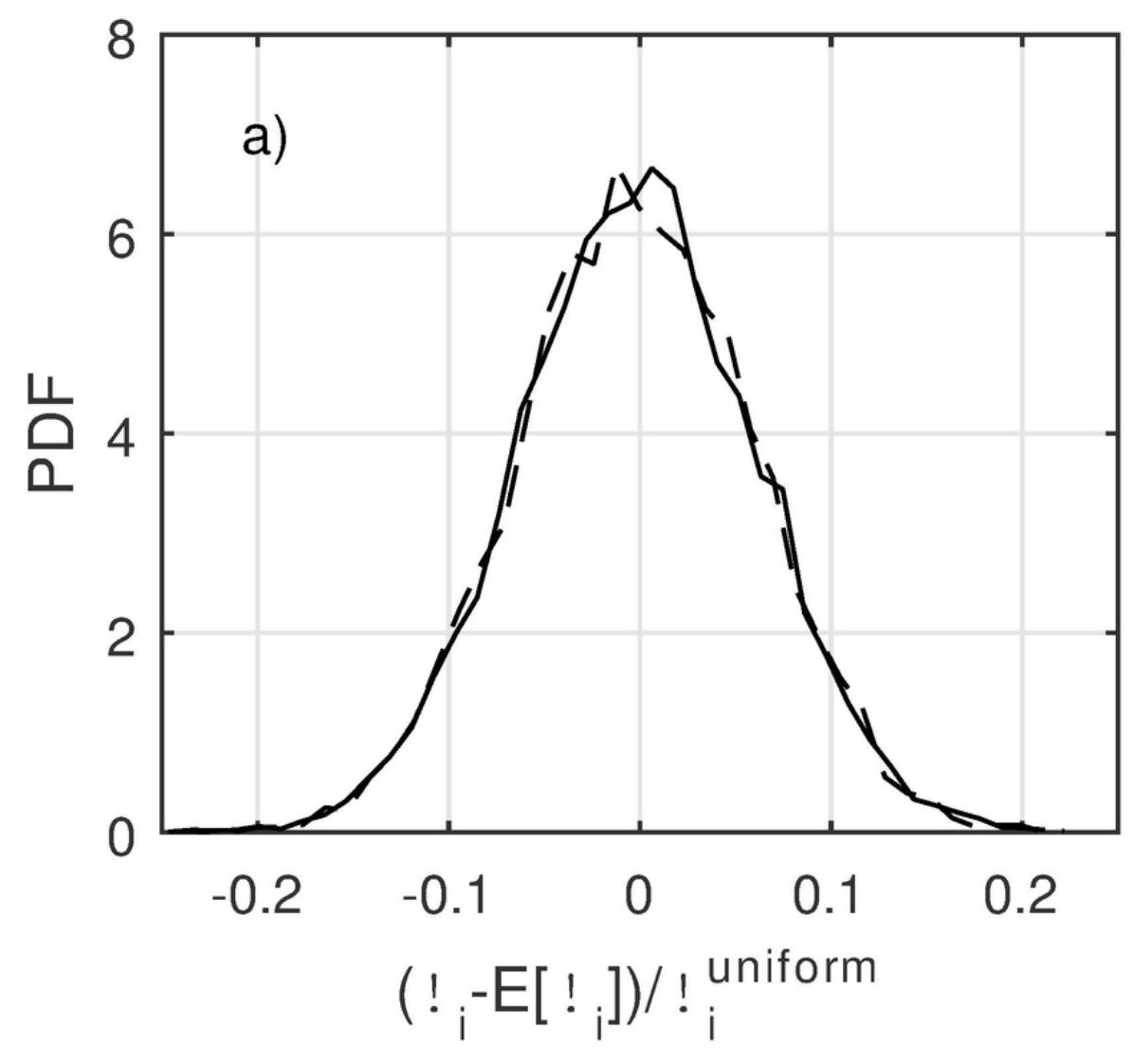

$78 \times 70 \mathrm{~mm}(300 \times 300$ DPI $)$ 


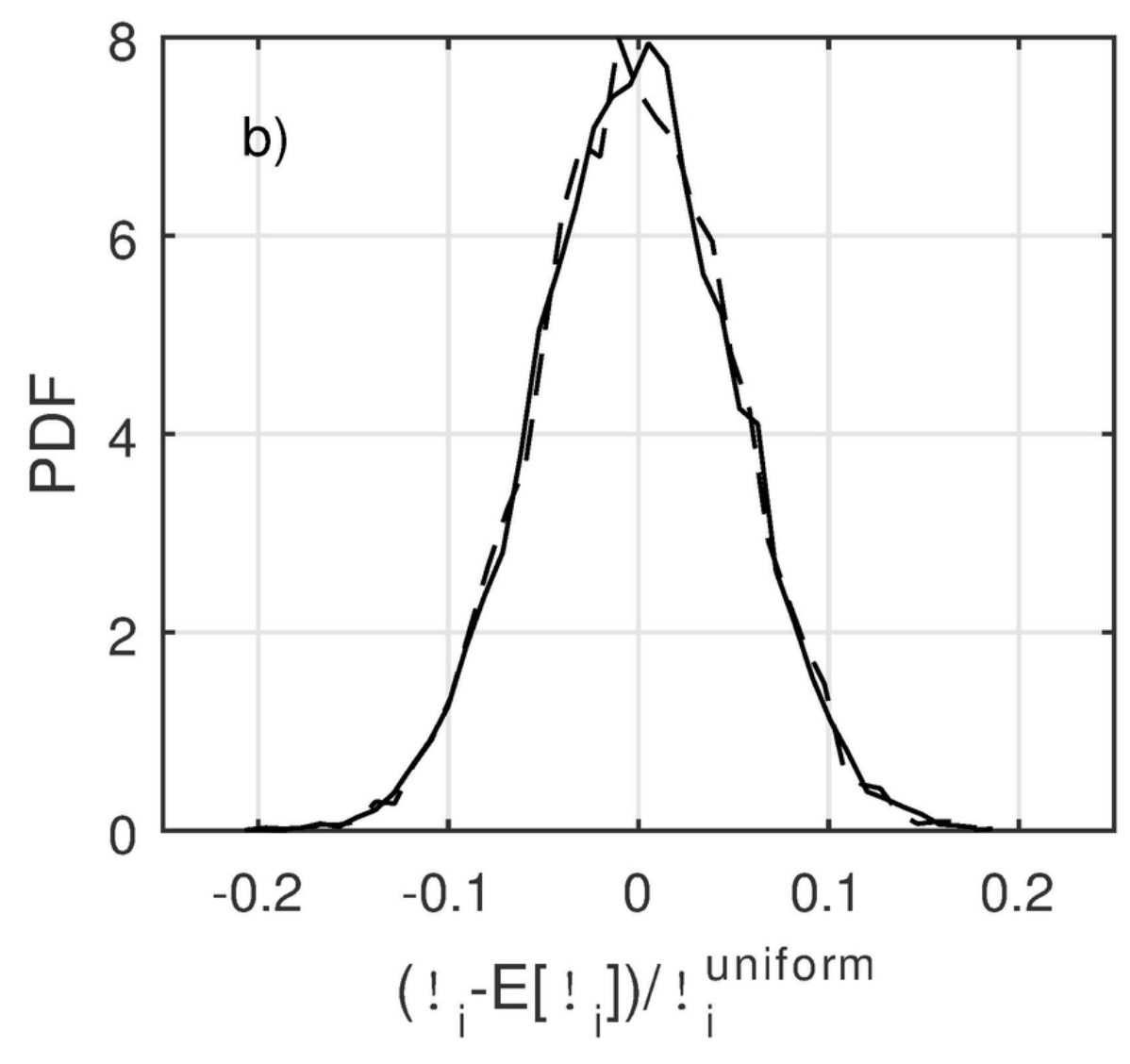

$78 \times 70 \mathrm{~mm}(300 \times 300$ DPI $)$

http://mc.manuscriptcentral.com/jvc 


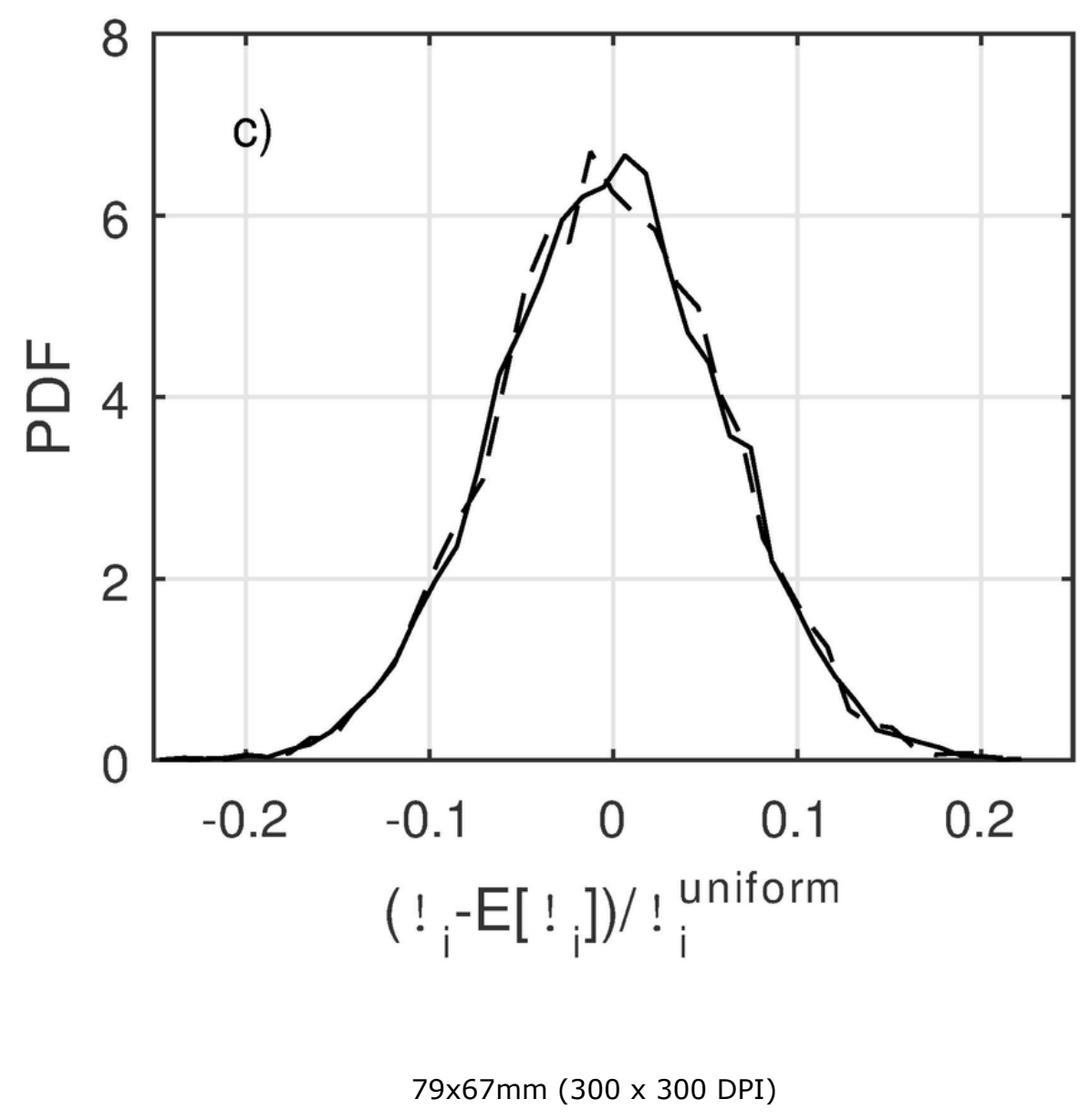

http://mc.manuscriptcentral.com/jvc 


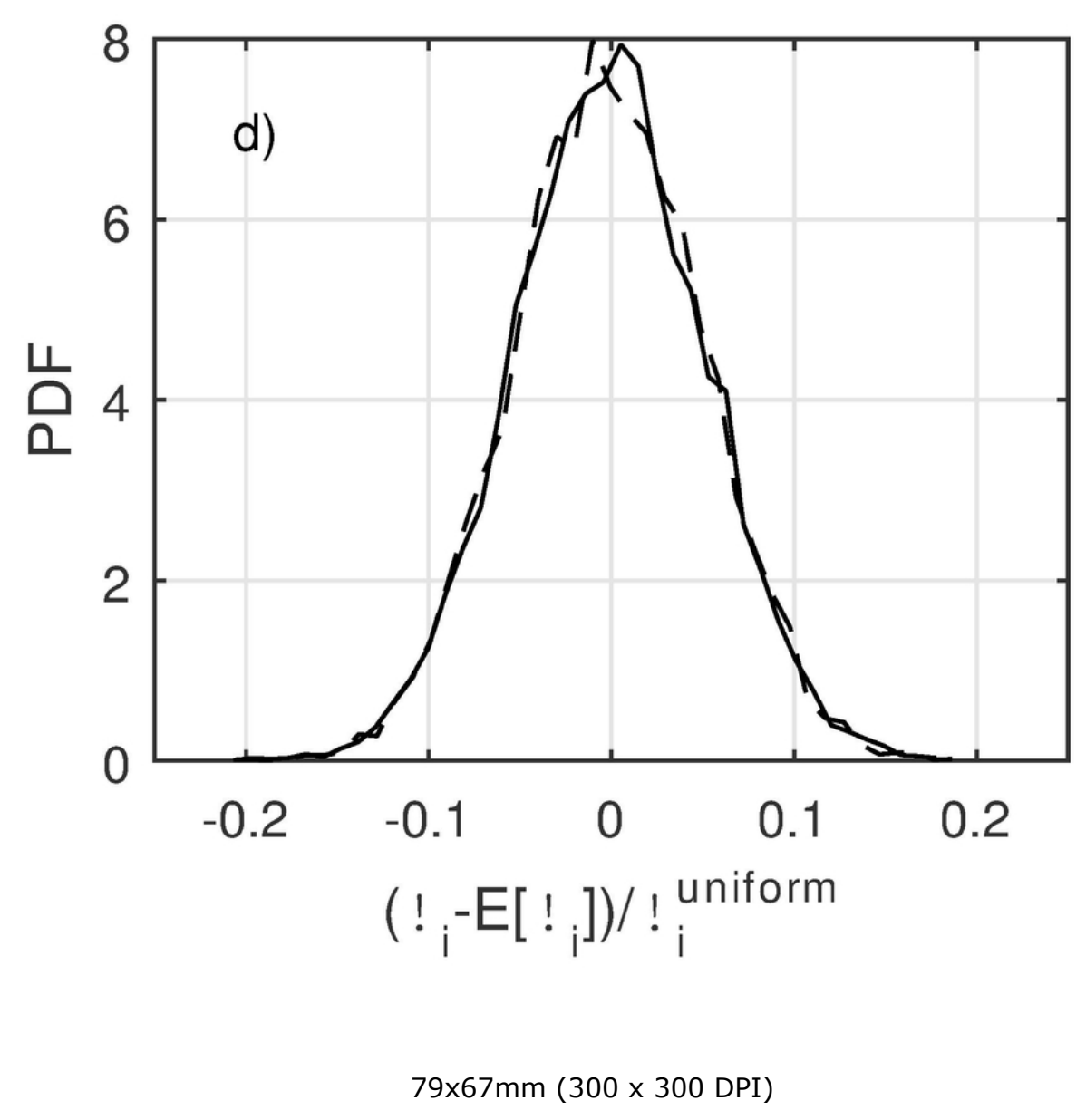

http://mc.manuscriptcentral.com/jvc 


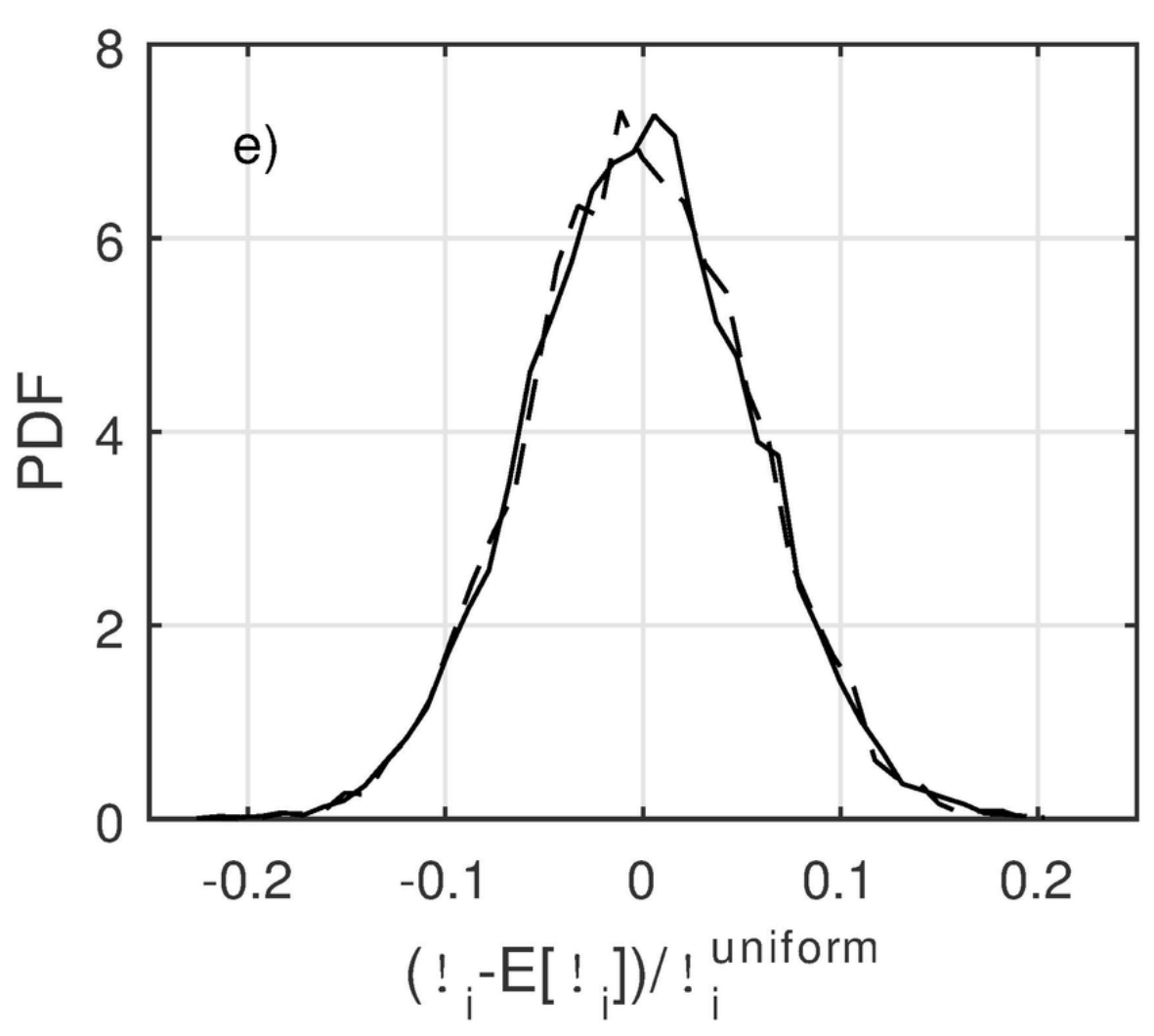

$82 \times 68 \mathrm{~mm}(300 \times 300$ DPI $)$ 


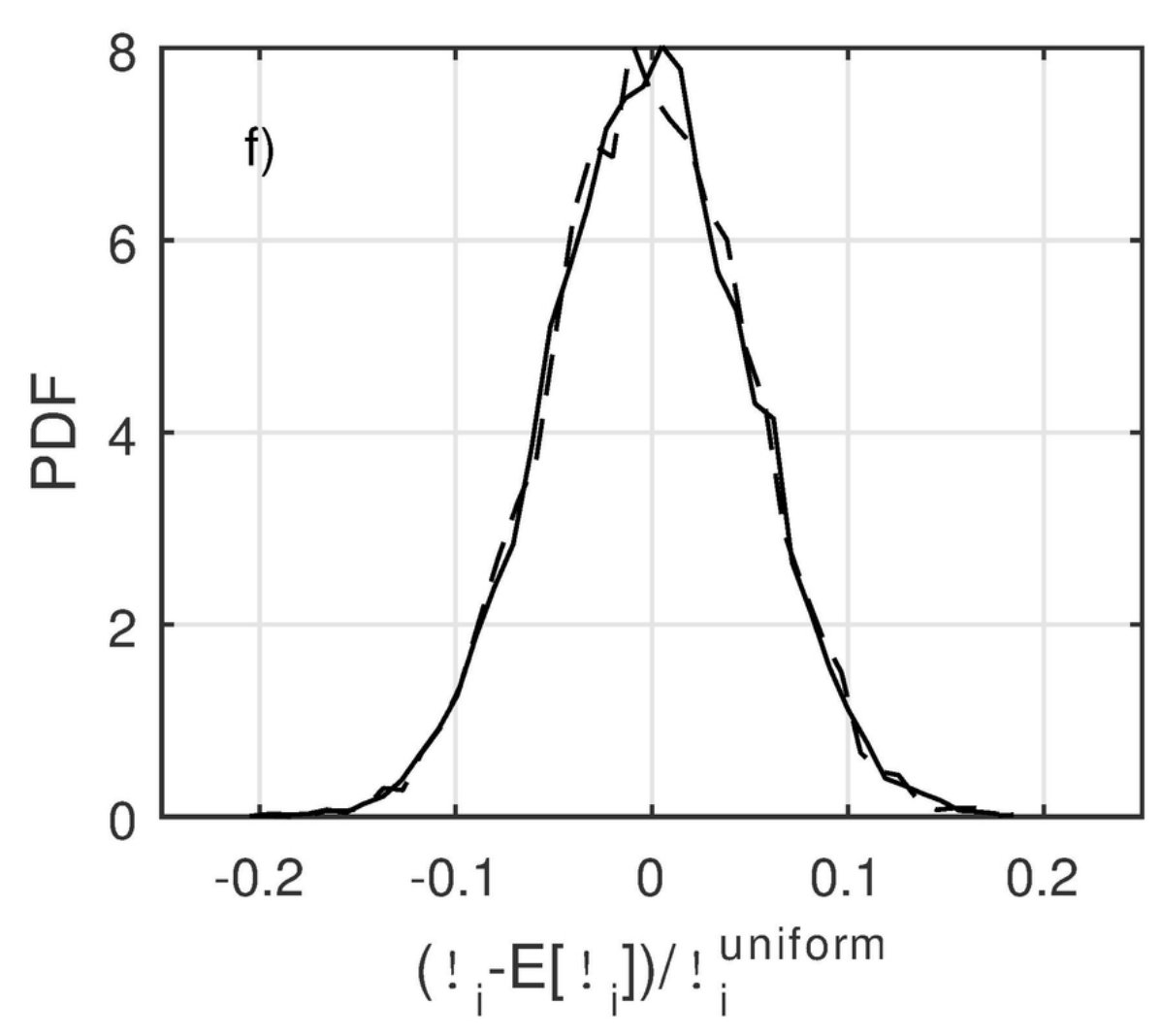

$82 \times 68 \mathrm{~mm}(300 \times 300$ DPI)

http://mc.manuscriptcentral.com/jvc 


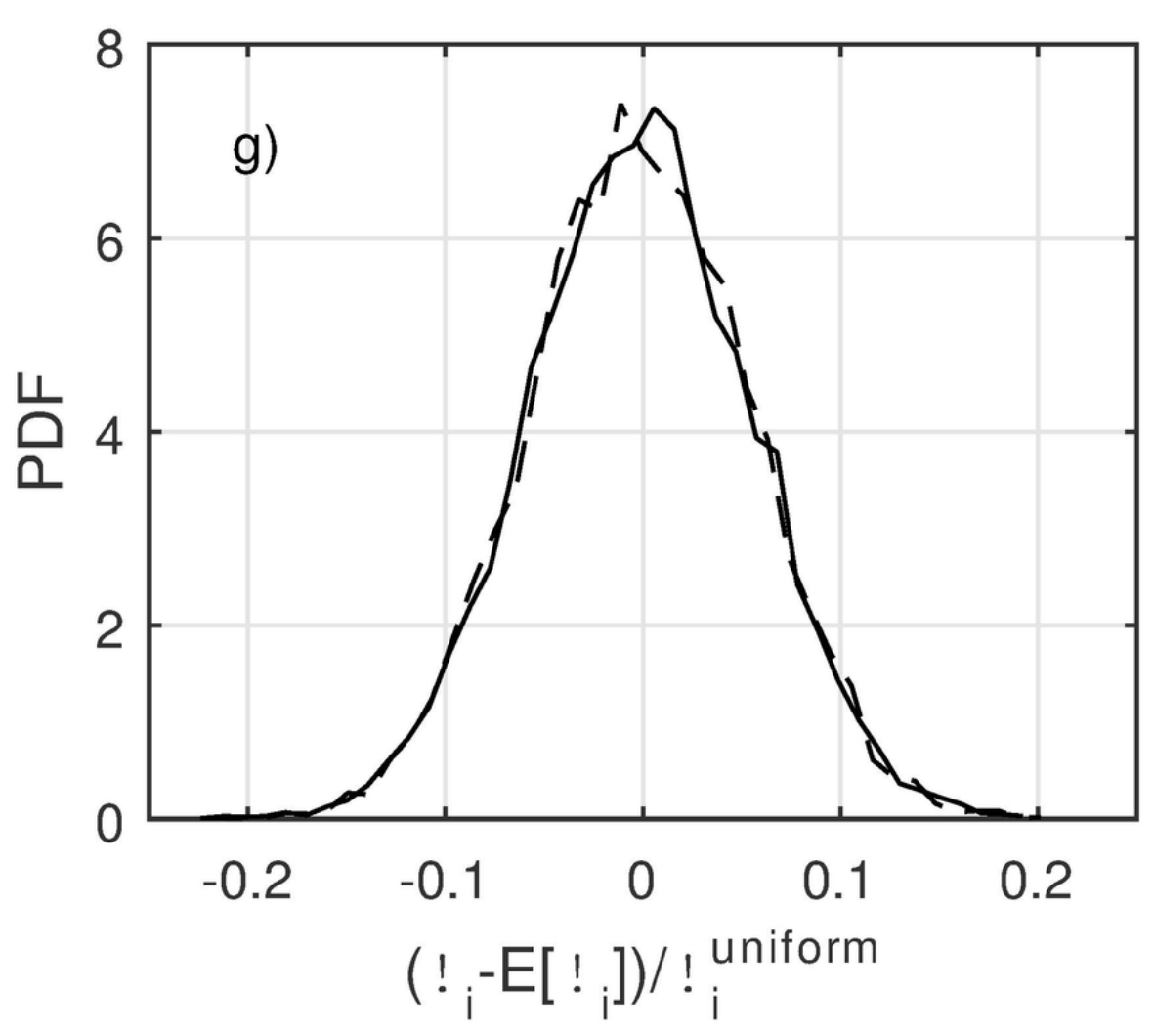

$82 \times 68 \mathrm{~mm}(300 \times 300 \mathrm{DPI})$ 